\title{
El Cabildo, Justicia y Regimiento de Arequipa durante el «bienio trascendental» (1808-1810)
}

\section{The Cabildo, Justicia, and Regimiento of Arequipa During the «Transcendental Biennium» (1808-1810)}

Fernando Calderón Valenzuela

El Colegio de México

fcalderon@colmex.mx

\section{RESUMEN}

Luego de conocerse la invasión francesa a España ocurrida a principios de 1808, las poblaciones hispanoamericanas reaccionaron unánimemente en defensa de su rey Fernando VII. Lo sucedido a continuación, entre 1808 y 1810, desató las contradicciones internas del sistema colonial. En este artículo abordo el caso de Arequipa durante aquel contexto, en particular la reacción de su Cabildo. Esta se debe entender en relación con lo acontecido en las ciudades vecinas - Cuzco, Puno, La Paz, Potosi - y en los centros de poder politico - Lima, Chuquisaca, Buenos Aires-. Así, sostengo que el fidelismo arequipeño mostrado por el Cabildo fue una estrategia para ganar autonomía y defender los intereses de su élite en la región, al mismo tiempo que se evitaba despertar conflictos al interior de la sociedad local. En aquel bienio, una serie de posibilidades aparecieron y cada sociedad encabezada por sus grupos dirigentes, optó por su propio destino. Palabras clave: Arequipa; Cabildo colonial; fidelismo; José Manuel de Goyeneche y Barreda; bienio 1808-1810

ABSTRACT

The Spanish-American colonies reacted in defense of King Ferdinand VII during the French invasion of Spain in 1808. The events that followed in 1808-1810 exposed the contradictions within the colonial system. In this paper

HISTORIOA XLI.1 (2017): 81-123 / ISSN 0252-8894

https://doi.org/10.18800/historica.201701.003 
I assess Arequipa's reaction in this context particularly its Cabildo, which must be understood in connection with the events in neighboring cities-Cuzco, Puno, La Paz, and Potosi - and in the centers of political power-Lima, Chuquisaca, and Buenos Aires. I argue that the loyalism of Arequipa's population was a strategy to gain autonomy and defend its regional interests while avoiding conflict at the local level. An array of possibilities emerged in that period, as a result of which Spanish-American societies, led by their ruling circles, decided their future.

Keywords: Arequipa; Colonial Cabildo; Spanish-American Loyalism; José Manuel de Goyeneche y Barreda; biennium 1808-1810

U na de las consecuencias de la instalación de las intendencias en el virreinato peruano fue la revitalización de los cabildos — debilitados debido a las continuas injerencias del virrey y los corregidores para controlar sus recursos económicos—. La labor de los intendentes, al dinamizar la función municipal, permitió que estas corporaciones continuaran siendo un medio de ascenso social y político. El poder municipal, en ese sentido, no fue adquirido a lo largo de la época virreinal, sino en sus últimos años. Así, si bien a partir de la crisis de la monarquía española (1808-1814), las luchas internacionales y regionales demandaron una atención especial, los libros de actas de los cabildos coloniales del Perú muestran la importancia que en este tránsito mantuvieron los temas locales y los mecanismos de defensa que se deseaban aplicar para evitar la propagación de los conflictos hacia la ciudad.

Son escasos los estudios sobre los cabildos coloniales peruanos, quizás debido al poco cuidado en la conservación de los libros de Cabildo y al reducido acceso a los archivos municipales. Se ha estudiado, por ejemplo, la composición del Cabildo secular de Arequipa en el siglo XVI. ${ }^{1}$ Además, gracias a la buena conservación de sus libros — casi todos en la Biblioteca Municipal de Arequipa-, con frecuencia aparece mencionado en la historiografía sobre la intendencia; estas referencias, sin embargo, suelen 
ser solo notas aclaratorias del comportamiento socioeconómico de la élite arequipeña. Por ello, en este artículo analizo la actuación corporativa del Cabildo de la ciudad de Arequipa entre 1808 y 1810, periodo considerado por la historiografía hispanoamericana como el punto de origen de los procesos independentistas ${ }^{2}$ y denominado por Manuel Chust como el «bienio trascendental». ${ }^{3}$ Centro mi interés en la reacción del Cabildo a las noticias sobre el establecimiento de juntas en el virreinato rioplatense, en tanto me permite perfilar las distintas posturas al interior del Cabildo y reevaluar el viejo mito de una élite arequipeña cohesionada y fidelista. ${ }^{4}$

Para lograrlo, los libros de actas del Cabildo son la fuente principal, aunque estos suelen registrar los acuerdos antes que las sesiones, pues estos conservan los temas tratados y los acuerdos a los que se llegaron, y no los debates que se producían en torno a ellos. En algunos casos, estos suelen presentarse en los expedientes que el procurador del Cabildo preparaba por cada tema, pero muchos de estos se han perdido o están dispersos. Uno de los que he utilizado para este artículo es el que formó el Cabildo para justificar su accionar frente a la Junta Tuitiva de La Paz. ${ }^{5}$ Muchos de estos expedientes se enviaban a Espańa para demostrar el proceder fidelista del cuerpo municipal y así obtener prerrogativas sociales

2 Aunque se ha atribuido dicho postulado a los trabajos de François-Xavier Guerra y Jaime Rodríguez O., tales hipótesis eran planteadas ya durante el siglo XIX en el libro pionero de Vicuña Mackenna (1971) y, a nivel local, por Cúneo Vidal (1978).

3 Utilizo esta denominación porque describe con precisión esta etapa que articula las reacciones producidas durante la crisis, algunas obviamente fidelistas y otras tantas imprevisibles que desconcertaron a los actores de la época (Chust 2007).

4 El fidelismo arequipeño fue atribuido a la presencia dominante de españoles, a su distanciamiento con las ideas revolucionarias de la Ilustración, a la falta de conciencia política entre los sectores populares y a la fortaleza de la Iglesia católica; estos factores evitaron conflictos entre los distintos sectores de la sociedad. Dicha imagen la encontramos en estudios como Zegarra 1973: 57-60; Cúneo Vidal 1978: 273-277, 282-291; Bermejo 1960: 355-416; y Rojas 2008. Según Rojas Ingunza, en la «sosegada» Arequipa «no se habían oído voces discordantes con la línea y temática política colonial» hasta 1814, cuando aparece Mariano José de Arce (2008: 156). Como bien demostró Chambers (2003: 25-53), estos argumentos son parte más de un mito que de una realidad.

5 «Expediente que trata de las providencias que en este Ylustre Cavildo ha dado con motivo de las ocurrencias de la ciudad de la Paz», Archivo de la Secretaria de la Municipalidad Provincial de Arequipa [en adelante ASMPA], Legajo 1809-4. 
(títulos, uniformes, ceremoniales) y beneficios económicos (control de rentas, autonomía de gasto). Aun así, es posible encontrar en ellos los conflictos entre las diferentes facciones enfrentadas por el poder local cuando a la crisis monárquica le siguió el vacío de autoridad que terminó fracturando al imperio español en América.

\section{EL CABILDO DE AREQUIPA}

Desde su fundación, en 1540, Arequipa contó con Cabildo para su gobierno. Sus miembros debían ser vecinos afincados con casa abierta y poblada, y los cargos se ejercían durante un año. ${ }^{6}$ Estaba compuesto por dos alcaldes ordinarios de vecinos (o de primer voto) y de ciudadanos (o de segundo voto), y según su origen existían tres tipos de regidores: perpetuos (cargos comprados), natos (contadores, tesoreros, básicamente funcionarios reales nombrados) y electivos. ${ }^{7}$ Su número estaba determinado por la cantidad de la población, siendo doce — número que le correspondía al Cabildo de Arequipa — su máximo legal.

En el siglo XVIII, el intendente Antonio Álvarez y Jiménez (17851796) reorganizó el Cabildo arequipeño y concedió nuevas rentas y funciones acordes con la Real Ordenanza de Intendentes (1782). Uno de sus objetivos era hacer más atractiva la labor municipal y lograr vender los asientos de regidores que desde hacía mucho estaban vacantes. De doce sillas disponibles para regidores, siete estaban ocupadas. Para conseguirlo debía obtener nuevos títulos para la ciudad y prerrogativas para quienes conformaban el Cabildo. La historia les había enseñado que la plata americana compraba favores y privilegios en la metrópoli; por lo tanto, fortalecer económicamente al Cabildo era el camino para su renacimiento. ${ }^{8}$

6 Sobre la legislación de las funciones, privilegios y demás asuntos tocantes a los cabildos véase Recopilación de leyes de los reinos de las Indias 1681: Libro IV, Título IX, y Libro V. 7 Los cargos electivos eran: alcaldes de primer y segundo voto, asesor del Cabildo, síndico procurador, alcalde de aguas y portero. Las elecciones al principio se llevaban a cabo el primer día del ańo y, a fines del siglo XVI, se trasladó al último día del año.

8 Un caso ejemplar fue el del Cabildo limeño, el cual consiguió nuevos privilegios concedidos por Carlos IV tras los donativos que entregó en 1802 y 1805 (Peralta Ruiz 2002: 105-142). 
El incremento de los ingresos del Cabildo les permitió a sus miembros utilizar una parte de ellos en donaciones que entregaban a la Corona. Esta era una de las razones por las que desde España se apoyó la libertad económica de dichos cuerpos. ${ }^{9}$ De este modo, los cabildos podían gastar con cierta autonomía los ingresos de propios y arbitrios, y pedir préstamos con su garantía.

Las reformas permitieron vigorizar al Cabildo en materia económica, pero también generaron conflictos, principalmente por el control del gasto. Esto se debía a la ambigüedad en la delimitación de funciones, en especial sobre el nombramiento de nuevos agentes de la administración colonial. ${ }^{10}$ Estas luchas las sufrió con mayor frecuencia el intendente Bartolomé María de Salamanca (1796-1811) y aumentaron ni bien empezó el siglo XIX. ${ }^{11}$

A pesar de los esfuerzos de Álvarez y Jiménez por atraer nuevos miembros al Cabildo, no logró su cometido. Salamanca no hizo mucho por cubrir los asientos vacantes, así que fue el mismo Cabildo quien tomó la decisión de pedir a la Corona — por medio de su representante en Espańa- que les otorgara permiso a sus regidores para vestir uniformes y diese medidas para proteger sus derechos y privilegios. De esta manera, se buscaba aumentar el interés de los vecinos notables en las regidurías. Además, el Cabildo insinuó con cautela sus discrepancias con el intendente, encargado de cubrir dichas plazas.

Desde 1808, conocida la crisis monárquica en el virreinato peruano, ${ }^{12}$ las disputas entre las élites y los intendentes se agravaron. Las primeras encontraron apoyo en las disposiciones tomadas por la Junta Central y el Consejo de Regencia. Como bien advierte John Fisher, mientras la estructura absolutista se encontró intacta, los intendentes gozaron de estabilidad, pero una vez que la crisis resquebrajó el sistema, las presiones

9 Fisher 1981: 209 y ss.

${ }^{10}$ Fisher 1981: 206-208; y Wibel 1975: 198-231.

${ }^{11}$ Véase Fisher 1968a; la Relación de gobierno de Salamanca que se cita a lo largo de este artículo puede consultarse en Fisher 1968b.

12 Sobre el arribo de estas noticias al Perú, véase Peralta Ruiz 2010: 89-113. 
contra dichas autoridades aumentaron y se inició un «periodo de confusión administrativa», caracterizada por la incertidumbre, las dificultades económicas y la desorientación surgida de la ejecución de reformas dadas por la Junta Central y la Regencia. ${ }^{13}$

Salamanca no fue ajeno a las críticas. Fue acusado por el comerciante español Santiago Aguirre de participar en el contrabando, vender las subdelegaciones y oprimir al Cabildo, mientras que esta corporación lo culpó de despotismo. El Consejo de Indias tomó la decisión de retirarlo; se dijo que el cambio se realizaba porque había excedido el tiempo de su gobierno de cinco ańos. Aunque Fisher otorga mayor importancia a las acusaciones entabladas por Aguirre y el Cabildo, ${ }^{14}$ pudo ser determinante el informe enviado por José Manuel de Goyeneche y Barreda, el 28 de abril de 1809, al Conde de Floridablanca y a la Junta Suprema de España e Indias tras finalizar la comisión que le encargó la Junta de Sevilla. En este, luego de resaltar los donativos hechos por el Cabildo arequipeño a la Corona, advirtió que:

Los cinco vecinos que forman el respeto y modelo de buen exemplo y bienes de la Ciudad acompañados del Asesor de la Yntendencia se me presentaron pidiendo rendidamente, suplicar a V. M. relevase a este Xefe que hace catorce ańos que los oprime sin ver ni tratar a nadie rodeado de asperezas de educación y de mal trato pues hay ocasiones en que su fibra ardiente nada disimula y sale de los límites que su carácter de Juez le precribe. ${ }^{15}$

Tras el levantamiento paceño de 1809, desde España llegó la orden de cambiar a Salamanca. Esta victoria del Cabildo arequipeńo se dio en un contexto más politizado a causa de la elección de un diputado para la Junta Central. Pero ¿quiénes fueron estos vecinos «modelo de buen exemplo y bienes» a los que se refería Goyeneche y Barreda, y de dónde provenía su poder?

La base económica que sustentaba a la élite arequipeña era la propiedad agrícola, dedicada sobre todo a la producción vitivinícola que

\footnotetext{
13 Fisher 1981: 213.

${ }^{14}$ Fisher 1968a: XI-XVI.

${ }^{15}$ Herreros de Tejada 1923: 456.
} 
abastecía de vinos y aguardientes producidos en sus valles a los centros mineros altoperuanos. La ciudad era la sede familiar y el centro de operaciones de sus actividades económicas. Estos grandes hacendados criollos utilizaron sus rentas para comprar las regidurías, con lo que lograron para sí el control del Cabildo. A pesar de las alianzas matrimoniales y los vínculos económicos con comerciantes y burócratas, solo ocho peninsulares fueron elegidos alcaldes de Arequipa desde 1780 hasta 1824 - todos ellos eran comerciantes y dos, además, funcionarios reales; solo un peninsular compró una regiduría- Los descendientes criollos de estas alianzas fueron quienes controlaron el Cabildo a principios del siglo XIX. Dice John Wibel que estos sucesores, obligados por su precaria situación económica producto en parte de la fragmentación del patrimonio familiar entre numerosos herederos, intentaron ingresar a la carrera burocrática. ${ }^{16}$ En cualquier caso, algunos de ellos fueron lentamente escalando posiciones a partir de su labor profesional e ingresaron al Cabildo por elección municipal y no por compra de regidurías.

Uno de los casos más llamativos es el de Nicolás Araníbar. Nacido en Locumba, era nieto de un oficial real español, estudió leyes en Lima y trabajó en la Real Audiencia. Fue elegido asesor del Cabildo arequipeño entre 1808 y 1810, y, en 1811, diputado por Arequipa en las cortes de Cádiz, aunque no llegó a viajar por problemas económicos. En 1812, fue alcalde de segundo voto y, un año después, alcalde de primera nominación del ayuntamiento constitucional de la ciudad. Miembro de una de las familias más representativas de Arica, sus vínculos parentales lo unían con grandes familias arequipeñas, como los Rivero, y gozaba de prestigio social.

Por otro lado, Manuel Gregorio Rivero y Ustáriz, hijo del subdelegado de Arica Antonio Salvador de Rivero y Araníbar, primo de Nicolás, se casó con Ángela Tristán y Bustamante, hija de Domingo Tristán y Moscoso, uno de los miembros más influyentes de la élite arequipeña y del Cabildo en el mismo periodo municipal que Araníbar. Es evidente la existencia de una suerte de alianza entre Tristán y Moscoso, Araníbar y la familia 
Rivero; a ellos considero los conductores del Cabildo durante el tiempo de nuestro estudio. Además, Tristán y Moscoso no solo disfrutaba de prestigio social, sino también de recursos económicos. ${ }^{17}$

Por su antigüedad, Francisco José de Rivero y Benavente era el regidor decano del Cabildo — el primero entre los regidores, en otras palabras-. Le tocaba suplir a los alcaldes cuando se ausentaban y, en las ceremonias, reemplazaba al alférez real Manuel Flores del Campo, notable hacendado de Camaná, porque este solía pasar más tiempo administrando sus propiedades costeñas. Los otros regidores perpetuos eran el alguacil mayor Ramón Morante, el alcalde provincial Agustín de Abril y Olazábal, José Ramírez Zegarra, Lucas Ureta y Fernando García González. ${ }^{18}$

En noviembre de 1809, Mariano de Ureta y Rivero, sobrino de los regidores Lucas Ureta y Francisco Rivero y Benavente, pagó quinientos pesos por la compra de una regiduría perpetua. ${ }^{19}$ Aunque no se puede afirmar la existencia de una coincidencia política entre todos ellos, se fue constituyendo un frente familiar con base en los Rivero. ${ }^{20}$ Esta familia de criollos, descendientes de hacendados, eran en su mayoría abogados sin grandes propiedades ni inversiones comerciales, por lo menos no comparables con los bienes de los Goyeneche o los Tristán. Asimismo, tenían una activa participación en las sesiones del Cabildo, pues, como

${ }^{17}$ Sobre la genealogía de los alcaldes de Arequipa y los vínculos familiares entre ellos, véase Martínez 1946.

${ }^{18}$ En 1805, el virrey Avilés escribió al Cabildo indicando que, a pedido del rey, se presenten cuatro candidatos para obtener títulos de Castilla; el Cabildo acordó presentar a Flores del Campo, quien era regidor desde 1779, a Ramírez Zegarra, regidor desde 1767, y a Rivero y Benavente, regidor desde 1765; además, también presentó al coronel José Menaut, al teniente coronel Juan Manuel de Bustamante, a Bernardo Gamio y al teniente Mariano González de Bustamante, todos ellos importantes hacendados arequipeños. Sesiones del 28 de noviembre y 12 de diciembre de 1805, Biblioteca Municipal de Arequipa [en adelante BMA], Libro de Actas del Cabildo [en adelante LAC], n. 26. ${ }^{19}$ Título de Regidor Perpetuo a favor de Mariano de Ureta y Rivero, BMA, Libro de Tomas de Razón, n. ${ }^{\circ} 3$.

${ }^{20}$ Manuel José de Rivero y Araníbar, primo de Rivero y Benavente y tío de Ureta y Rivero, se casó en 1810 con Josefa Abril y Olazábal. Sobre las relaciones endogámicas de la élite arequipeña, véase Wibel 1975: 480-494. 
Flores del Campo, los regidores Abril y Olazábal y García González se ausentaban con frecuencia de la ciudad. ${ }^{21}$

Según Mary Gallagher, Tristán y Moscoso, Araníbar y la familia Rivero representaban a un sector de la élite contrario al absolutismo monárquico, pues buscaban introducir en la ciudad ideas separatistas en contraposición al obispo Luis Gonzaga de La Encina, al deán García de Arazuri y a José Manuel de Goyeneche y Barreda. ${ }^{22}$ Una postura intermedia era la de Hipólito Unánue, asesor de Abascal, y la familia Ustáriz. ${ }^{23}$ La posición de Goyeneche y Barreda representaba la de toda su familia; en cambio, Pío Tristán se inclinó más al monarquismo de los Goyeneche que hacia el radicalismo de su hermano Domingo. ${ }^{24}$ Como advierte Wibel, la practicidad de la élite arequipeña evitó grandes conflictos con las autoridades coloniales y a nivel interno, pues la posición adoptada tenía más de interés y autodefensa que de fuerte convicción. ${ }^{25}$

Lo cierto es que, si durante estos años el Cabildo estuvo bajo el control del sector radical, la presencia de Goyeneche y Barreda, de quien hablaremos más adelante, influyó en el comportamiento del Cabildo y de las instituciones coloniales arequipeñas. Además, los miembros del Cabildo

${ }^{21}$ Fernando García González no suele figurar entre los firmantes de las sesiones del Cabildo, aunque aparece casi siempre durante las elecciones a fin de año.

${ }^{22}$ Gallagher 1978: 242-244. Además, Wibel señala que los burócratas criollos se sentían desplazados jerárquicamente por los peninsulares y por otros criollos con capacidad para comprar cargos públicos; así lo demuestran las rivalidades por el cargo de subdelegado y los conflictos entre estos y los intendentes (Wibel 1975: 161-197).

${ }^{23}$ Este sector intermedio estaba compuesto por ilustrados católicos, uno de ellos fue Mariano Eduardo de Rivero y Ustáriz, quien luego de estudiar en Europa retornó a América donde, como Hipólito Unánue, desempeñó diferentes cargos públicos.

${ }^{24}$ Uno de los mecanismos que usó Pío para evitar la dispersión de la propiedad fue su matrimonio con su sobrina Joaquina, hija de su hermana Petronila y de Manuel Flores del Campo, en 1809. Por otro lado, tras la invasión de las tropas de José Castelli al Alto Perú, el virrey Abascal acusó al intendente de La Paz, Domingo Tristán de no haberlas enfrentado. En sus memorias, Rufino Echenique menciona que su primo Goyeneche y Barreda y su hermano Pío, "para cohonestar su falta», lo restablecieron en su puesto (Echenique 1952: 1-3, 343). En 1815, el capitán de milicias de Arequipa y Arica, Juan Agustín Lira, afirmó que encontró en Majes a Domingo, quien junto a los pobladores del lugar «eran adictos a nuestra suspirada Independencia» (Lira 1834).

${ }^{25}$ Wibel 1975: 232-268. 
priorizaron el enfrentamiento contra el intendente. En ambos casos, los radicales encabezados por Tristán y Moscoso y Araníbar jugaron un papel destacado. ${ }^{26}$

En este periodo, los temas tratados por el Cabildo discurrían entre la epidemia de hidrofobia que afectaba a la población — se organizó una matanza de perros_-; la distribución de la vacuna contra la viruela; la reparación del puente y el arreglo de las casas capitulares; ${ }^{27}$ y los ceremoniales que se hicieron, primero, al recibir la ciudad el título de Fidelísima gracias al apoyo que esta brindó para la lucha contra el levantamiento de Túpac Amaru II y la pacificación del Alto Perú, ${ }^{28}$ y, segundo, por el recibimiento de Abascal como nuevo virrey. ${ }^{29}$ Las noticias sobre la abdicación de Carlos IV y el paso de Goyeneche y Barreda por la ciudad ${ }^{30}$ ocuparon mayor atención que los conflictos acaecidos en el virreinato del Río de la Plata entre 1806 y 1807. Pero todas estas cuestiones no impusieron una mayor frecuencia en las sesiones, por lo menos no hasta 1809, cuando se conoció el levantamiento de La Paz.

A principios del siglo XIX, el Cabildo arequipeño, politizado tras los sucesivos conflictos internos entre las autoridades locales y fortalecido por algunas libertades económicas, revelaba mayor interés por el gobierno local. Además, cuando algún conflicto externo afectaba su seguridad y sus intereses, lucía un compacto espíritu de cuerpo y ocultaba las facciones que en su interior existían. ${ }^{31}$ Las crisis políticas,

${ }^{26}$ Fisher menciona una carta del Cabildo de Arequipa de 1809, en la cual sus miembros se quejaban del intendente Salamanca y, señalando que no lo habían hecho antes por considerarlo uno de los favoritos de Manuel Godoy, lo acusaron de mantener conflictos contra Domingo Tristán por no apoyarlo en su proyecto de ser elegido diputado por Arequipa (Fisher 1968a: XIV-XV).

27 Sesión del 17 de octubre 1808, BMA, LAC, n. ${ }^{\circ} 26$.

${ }^{28}$ Sesión del 1 de junio de 1807, BMA, LAC, n. ${ }^{\circ} 26$.

${ }^{29}$ Sesiones de abril a julio de 1806, BMA, LAC, n. ${ }^{\circ} 26$.

${ }^{30}$ Noticia de la abdicación de Carlos IV, sesión del 12 de septiembre de 1808, BMA, LAC, n. ${ }^{\circ}$ 26; y Noticia de la llegada de Goyeneche a Arequipa, sesión del 7 de noviembre de 1808, BMA, LAC, n. 26.

${ }^{31}$ Este comportamiento cohesionador entre la élite arequipeńa, especialmente entre quienes controlaban el Cabildo, se puede notar también en la denominada «rebelión de los pasquines», que tuvo lugar a inicios de 1780. Dice Wibel: «despite creole resentment 
así, fueron utilizadas por el Cabildo para obtener mayores privilegios y reformas en la parte que afectaban sus ambiciones. En otras palabras, si bien este tenía la responsabilidad de mantener la cohesión interna frente a los conflictos que intentaban destruir el orden colonial, también era el espacio donde los grupos que componían la élite local defendían sus propios proyectos y se oponían a determinadas medidas que restringían o negaban sus prerrogativas. De esta manera, el gobierno municipal osciló entre defender la posición de la élite que lo dirigía y obstruir las medidas que atentasen contra su autonomía.

\section{EL BIENIO TRASCENDENTAL}

El año de 1808 es considerado por la historiografía hispanoamericana como el inicio la crisis de la monarquía española. Su primera fase comprende de 1808 a 1810, momento trascendental para el fortalecimiento del sector liberal español y la construcción de una monarquía constitucional. Además, aunque la reacción colonial frente a estos eventos fue de un fidelismo aparentemente unánime en defensa de la monarquía borbónica encabezada por Fernando VII, este sirvió a los diversos actores políticos americanos para defender sus propios proyectos políticos autonomistas en la América española. ${ }^{32}$ Entonces, son dos los temas que sobresalen y caracterizan al bienio trascendental: la difusión y el uso de las noticias, y el ambiente sociopolítico de la América española, especialmente tenso por el anterior afán reformista borbónico.

Sobre el virreinato peruano, Víctor Peralta Ruiz señala que esta coyuntura marca el inicio de un periodo de incertidumbre, caracterizado

toward peninsular merchants and officials, both groups were well aware of the advantages of joining forces to place the blame for Arequipa's rioting on Pando [...], they understood the necessity for unity in order to prevent exposure of the official corruption characteristic of Semanat's immediate circle or the tax evasion typical of the region's landed and mercantile élites» (1975: 47).

${ }^{32}$ Dicha «aparente reacción fidelista» se podría explicar por ser las capitales de virreinatos, las sedes de reales audiencias y las capitanías generales, los espacios que se han estudiado con mayor detalle; además, se debe considerar que como base informativa se ha usado principalmente la documentación producida por oficiales reales. 
por las dificultades en la comunicación y por el uso político de las noticias. ${ }^{33} \mathrm{~A}$ la propaganda fidelista y triunfalista de Abascal se opusieron las noticias desalentadoras traídas por franceses y británicos y utilizadas por los americanos contrarios a la política absolutista. En 1810, la unánime respuesta en favor del secuestrado rey español se mantuvo, pero el reconocimiento a las instituciones que desde Espańa pretendían controlar América comenzó a ser criticado y, en algunos casos, negado. Fue evidente el vacío de autoridad, por lo que emergieron proyectos autonomistas que decían defender los derechos del rey en contra de la Regencia y las Cortes: las culpaban de usurpación o de afrancesamiento. La coyuntura política cambió y con ella su extensión militar. Lentamente, las provincias americanas reclamaron su derecho al autogobierno tal como sucedió en la Península tras la invasión francesa y las abdicaciones de Bayona. Este proceso quedó evidenciado por el fortalecimiento de una propaganda de corte patriótico y encargada de desmentir las noticias difundidas por las autoridades virreinales. ${ }^{34}$

Sobre el ambiente sociopolítico de la América española, Manuel Chust sostiene que los acontecimientos sucedidos durante este bienio no pretendían la independencia ni se distinguían por ser una confrontación entre peninsulares y americanos, o espańoles contra criollos, por lo menos no hasta mediados de 1810 tras la formación de las juntas de Buenos Aires y Caracas. ${ }^{35}$ Sin embargo, se debe advertir que las acciones previas contra la autoridad colonial, si bien no implican la negación del monarquismo, fueron la base de futuros proyectos autonomistas

\footnotetext{
33 Peralta Ruiz 2007: 139.

${ }^{34}$ Ciertamente, Peralta Ruiz sobreestima el papel de la propaganda fidelista en el proceso de politización (el cual podemos rastrear desde la instalación de las intendencias y se hace evidente en el aumento de las sesiones del Cabildo y las nuevas atribuciones que estos recibieron) y desestima la situación tensa en el Surandino, previa a la crisis de la monarquía y tras los levantamientos indígenas del siglo XVIII. No olvidemos que el Bajo y el Alto Perú eran zonas militarizadas desde 1780, y evitar los sobresaltos que condujeran a rebeliones no solo era responsabilidad de los intendentes, sino también de los cabildos y toda autoridad local. Es frecuente hallar en los documentos las advertencias para evitar las innovaciones que pudiesen generar malestar.

${ }^{35}$ Chust 2007: 23-27.
} 
y separatistas, pues revelaron las rivalidades políticas, económicas y sociales entre los españoles americanos y los peninsulares. ${ }^{36}$ Mientras la monarquía española respetó los privilegios y aseguró el estatus social de los sectores altos, su autoridad no fue discutida, mas cuando esta dejó de cumplir tal rol, cada élite local buscó preservar su posición al interior de la sociedad. En momentos de crisis internacional, las sociedades suelen defender la única realidad tangible que conocen: su ciudad. ${ }^{37}$

¿Cómo reaccionó el Cabildo, Justicia y Regimiento de la ciudad de Arequipa ante lo acontecido en este bienio trascendental? A partir del arribo de información peninsular y cómo esta repercutió en las medidas adoptadas en América, Chust divide este bienio en tres fases: la primera comprende de julio a septiembre de 1808, cuando llegan las noticias de la proclamación de Fernando VII; la segunda, de abril a mayo de 1809, cuando se informa sobre la creación de la Junta Central y la participación americana en el gobierno; y la tercera, de mayo a junio de 1810, cuando se reporta la disolución de la Junta Central, la creación de la Regencia y la convocatoria a Cortes. Si seguimos estas fases para responder esta interrogante, notaremos que no se ajustan completamente al caso arequipeño, por lo que conviene hacer algunas aclaraciones.

La reacción del Cabildo, para comenzar, estaba vinculada con sucesos locales y regionales. Si bien frente a la incertidumbre inicial experimentada de manera semejante en toda América española se impusieron las respuestas de las principales capitales y ciudades aledañas, la reacción de Arequipa se relaciona con lo que ocurría en las poblaciones vecinas. En otras palabras, su conducta estaba condicionada por lo que sucedía en Lima, Charcas y Buenos Aires, pero se encontraba circunscrita a lo que ocurría en Cuzco, Puno, La Paz y Potosí. Además, como intendencia, intentaba mantener la tranquilidad dentro de su jurisdicción, especialmente frente a Tacna, Arica y Condesuyos; y, como partido, trataba de evitar la formación de grupos internos contrarios a la política virreinal. Por ello, dado que las circunstancias de cada localidad pueden variar,

${ }^{36}$ Lynch 2008: 9-43.

${ }^{37}$ Chiaramonte 2004: 177-178. 
es importante confrontar las tres fases propuestas por Chust con la realidad local y regional arequipeña.

PRIMERA FASE: JOSÉ MANUEL DE GOYENECHE Y BARREDA Y EL FIDELISMO EXALTADO

Esta fase comprende desde septiembre de 1808 —cuando llegaron las noticias sobre la proclamación de Fernando VII como rey de España, la invasión francesa, el secuestro de la familia real y la formación de juntas en la Península— hasta julio de 1809 — cuando se conocen las primeras noticias de los sucesos en Charcas-. En 1808, la reacción en defensa del rey supuso la existencia en la América española de fortaleza ideológica y política y respeto a las autoridades e instituciones coloniales. Quizás esta aseveración tenga mayor fiabilidad si estudiamos el comportamiento arequipeño. En parte, la presencia del brigadier Goyeneche y Barreda, quien llegó como enviado de la Junta de Sevilla en agosto de 1808 con la misión de hacer jurar lealtad a Fernando VII en los territorios americanos y de que se reconociera a la Junta de Sevilla como su autoridad superior, puede explicar tal proceder. Pese a que sus acciones en el virreinato del Río de la Plata fueron muy criticadas por las autoridades locales, la reacción arequipeña, y del sur peruano en general, fue distinta.

Conocida la misión que la junta sevillana encargó a Goyeneche y Barreda, en Arequipa se organizó rápidamente la juramentación al nuevo rey. La noticia de las abdicaciones se conoció el 12 de septiembre de 1808 por la vía de Buenos Aires y, el 30 del mismo mes, tras leerse un oficio del Cabildo de aquella ciudad donde se relataban en extenso las noticias de la invasión napoleónica, se acordó jurarle fidelidad a El deseado, «queriendo adelantarse todo para que se haga con la suntuosidad y demostración que acrediten en lo posible esos pensamientos de lealtad que tan gustosamente están gravados en los corazones de esta fidelísima ciudad». ${ }^{38}$

${ }^{38}$ Sesiones del 12 y 30 de septiembre de 1808, BMA, LAC, n. ${ }^{\circ} 26$. «Proclama dirigida por el Ylustre Cavildo Justicia y Regimiento de Arequipa al vesindario y havitantes de esta Ciudad; con motivo de la Proclamación del Señor D. Fernando VII Rey de España y de las Yndias», BMA, LAC, n. ${ }^{o}$ 26, ff. 134-135. 
El 3 de noviembre se realizó la ceremonia; es decir, se anticiparon a la orden del virrey que llegó recién cuatro días después.

En la sesión del Cabildo que trató sobre la misión de Goyeneche y Barreda, se resaltó su calidad de paisano: "con motivo de lo que se anuncia en los papeles públicos de tener esta ciudad la gloria de que el enbiado por la Junta Suprema de Sevilla que representa la Nación, es hijo de la Patria, mando en su suelo, y de una de las primeras Familias ilustres» ${ }^{39}$ Después de enterarse de su llegada a la ciudad, en las elecciones del Cabildo del 31 de diciembre de 1808, se le eligió por unanimidad alcalde ordinario de primer voto. ${ }^{40}$ Goyeneche y Barreda agradeció el nombramiento, pero declinó ejercerlo debido a la comisión que desde Sevilla se le encomendó. ${ }^{41}$ Luego de nombrársele presidente de la Audiencia del Cuzco y comandante de los ejércitos pacificadores del Alto Perú en 1809, el apoyo brindado por el Cabildo y la ciudad figuró como el respaldo a un miembro de la sociedad arequipeña, y Goyeneche y Barreda supo explotar esta situación a su favor. ${ }^{42}$

Cuando ingresó a Arequipa, el 8 de enero de 1809, recibió un oficio del capitán de milicias Rafael Rospillosi y de Juan Tordoya y Montenegro en el que le ofrecían un refuerzo de cuatro mil a seis mil hombres para luchar contra Francia; $;{ }^{43}$ aunque a lo mejor solo se trató de una muestra para ganar notoriedad — pues, según se sabe, no se realizó dicho ofrecimiento-, es una prueba del fidelismo exaltado que vivió la ciudad durante esas fechas. ${ }^{44}$ Goyeneche y Barreda estuvo once días en Arequipa,

${ }^{39}$ Sesión del 7 de noviembre de 1808, BMA, LAC, n. ${ }^{\circ} 26$.

${ }^{40}$ Sesión del 31 de diciembre de 1808, BMA, LAC, n. ${ }^{\circ}$ 26. Inclusive, el Cabildo acordó disponer de sus rentas de propios y arbitrios para cubrir la media anata que le correspondía pagar a Goyeneche y Barreda tras haber sido elegido alcalde; Sesión del 15 de abril de 1809, BMA, LAC, n. ${ }^{\circ} 26$.

${ }^{41}$ Sesión del 1 de enero de 1809, BMA, LAC, n. ${ }^{\circ} 26$.

${ }^{42}$ El Cabildo de Arequipa no fue el único que distinguió a Goyeneche, sino que también fue nombrado regidor perpetuo del Cabildo del Cuzco y alcalde de primer voto del de Camaná.

${ }^{43}$ Herreros de Tejada 1923: 156-157.

${ }^{44}$ Oficio del capitán de milicias Rafael Gavino Rospillosi y de Juan Tordoya y Montenegro, 2 de diciembre de 1808, Archivo Histórico Nacional de Espańa, Estado, 54, B-100, n. ${ }^{\circ} 44$. 
hospedado en casa de sus padres. Luego partió a Lima en compañía de su hermano Pedro Mariano, miembro de la Audiencia del Cuzco. En Arequipa, recibió la visita de las autoridades locales, entre ellas la del asesor de la Intendencia y de cinco vecinos quienes le pidieron que interceda ante el rey para retirar de su cargo al intendente Salamanca, como ya se señaló.

Otro elemento que coadyuvó a la reacción fidelista del Cabildo fue la presencia en la ciudad del marqués Gabriel Avilés, exvirrey del Perú desde agosto de 1807. La estadía de tan notable personaje en la ciudad, físicamente débil, fue decisiva para el control de los asuntos públicos que el Cabildo tomó. Avilés había sido comisionado por Abascal para que viajase a Buenos Aires y se encargue del gobierno de dicho virreinato luego de las invasiones inglesas, pero, cuando llegó a Arequipa, prevenido por posibles resistencias contra su nombramiento, decidió quedarse en la ciudad, donde se enteró de la derrota británica y del nombramiento de Santiago Liniers como nuevo virrey del Río de la Plata. Avilés decidió permanecer en Arequipa junto con su séquito mientras preparaba su viaje hacia España. ${ }^{45}$

La presencia del marqués es importante porque, por ejemplo, cuando el 12 de agosto de 1809 la Junta Tuitiva comunicó al Cabildo de La Paz el nombramiento de Baltazar Hidalgo de Cisneros como nuevo virrey del Río de la Plata, llevado a cabo en Colonia del Sacramento y no en Buenos Aires como establecía el protocolo, ${ }^{46}$ consultó su validez,

45 Según Manuel de Mendiburu, el clima arequipeño cayó bien al anciano exvirrey (18741890, I: 412-427); sin embargo, en la carta que escribió Avilés al Cabildo de Arequipa, en octubre de 1809 , señaló que su estancia se debió a las circunstancias adversas para emprender viaje a Espańa, pues los mares estaban poblados de navíos ingleses. Agregó en dicha carta que su presencia fue siempre temporal y que su edad y salud le impedían desempeńar labores políticas, a pesar de que Abascal le había pedido hacerse cargo de la intendencia arequipeńa (Expediente sobre la partida de Avilés de Arequipa, ASMPA, Legajo 1809-4).

${ }^{46}$ Los miembros de la junta consideraron que este hecho "trae consigo un carácter de inverosimilitud, que si solo por esta desorganizada noticia se le reconociese por Gefe de este Virreynato, se cometería el maior desacato contra las Leyes constitucionales de Nuestro Govierno", pues era la Audiencia de Buenos Aires quien debía reconocer los sellos reales de tal nombramiento ("Expediente que trata de las providencias», ASMPA, Legajo 1809-4, ff. 90-93). 
en primer lugar, al marqués de Avilés, quien «por sus altos respetos, y por la integridad, desinterés, zelo, lealtad y patriotismo, con que se ha conducido en el gobierno de los dos virreynatos de este continente del sur, nos instruirá juiciosamente en unos puntos tan espinosos»; ${ }^{47}$ solo después fueron consultados el brigadier Goyeneche y Barreda, por estar autorizado por la Junta de Sevilla, las audiencias de Lima y Cuzco, y el virrey Abascal. ${ }^{48}$ Asimismo, el exvirrey participó en las ceremonias más importantes organizadas por el Cabildo, como la celebración del 10 de agosto de 1807 por el triunfo sobre los ingleses en el Río de la Plata. ${ }^{49}$ Además, con el arribo de las noticias de la abdicación de Carlos IV y la organización de la ceremonia de juramentación al nuevo rey, el Cabildo acordó que sea el marqués de Avilés quien haga las veces de alférez real, «conforme se hace con los Excelentísimos Señores Virreyes». ${ }^{50}$ Se nombró una comisión para hacerle la invitación y, aunque no aceptó dicha distinción — pues en la ceremonia del 3 de noviembre fue el alférez real quien cumplió con normalidad su función-, sí participó en las misas de acción de gracias ofrecidas a raíz de los supuestos triunfos espańoles en la Península, comunicados por Abascal. ${ }^{51}$

El virrey confió en los resultados de las labores que encomendó a Avilés y este lo mantuvo enterado de los acuerdos y sucesos en la ciudad. En sus memorias, Abascal señaló que, tras el levantamiento de La Paz, le pidió ayuda:

Escriviendo a los Xefes y personas de su confianza, residentes en uno, y otro vireynato, con el pulso y madures, que había acreditado en ambos gobiernos quanto considerase útil, necesario y conveniente al logro de un objeto de tanta recomendación, e importancia al servicio del Rey, y a la felicidad de los mismos Pueblos, sin extenderme a más indicaciones ni a otros encargos, por consideración a su quebrantada salud; pero que esperaba desde luego sus avisos y las advertencias, que devían conducirme al acierto que deseaba. ${ }^{52}$

\footnotetext{
47 «Expediente que trata de las providencias», ASMPA, Legajo 1809-4, f. 90.

${ }^{48} \mathrm{Ib}$.

${ }^{49}$ Sesión del 11 de agosto de 1807, BMA, LAC, n. ${ }^{\circ} 26$.

${ }^{50}$ Sesión del 31 de octubre de 1808, BMA, LAC, n. ${ }^{\circ} 26$.

${ }^{51}$ Sesiones de noviembre y diciembre de 1808, BMA, LAC, n. ${ }^{\circ} 26$.

${ }^{52}$ Abascal 1944: 5-7.
} 
La presencia de Goyeneche y Barreda y de Avilés en Arequipa fue utilizada por los miembros del Cabildo para fortalecerse políticamente. Probablemente sabían que Goyeneche y Barreda intercedería ante la Corona en defensa de los vecinos arequipeños y en futuros nombramientos ${ }^{53}$ — como ocurrió con los hermanos Tristán-, mientras que Avilés limitaría el poder del intendente y, por su edad, evitaría confrontaciones con la élite local; incluso su mayordomo, Manuel Fernández de Arredondo, contrajo matrimonio con una arequipeña. ${ }^{54}$

La élite local debía demostrar su fidelismo, pero las manifestaciones, antes que económicas, fueron discursivas y ceremoniales. Acaso la rapidez con que efectuaban sus donativos se relacionaba con cuán urgente era la resolución de sus intereses. En la crisis peninsular de 1808 la reacción no fue inmediata, pues, enterados de los «ultrajes» cometidos por los franceses en septiembre de aquel año, ${ }^{55}$ se esperó la orden del virrey — que llegó en noviembre - ${ }^{56}$ para levantar erogaciones y se reiteró el pedido en las siguientes sesiones. ${ }^{57}$ El fidelismo exaltado por la visita de Goyeneche y Barreda no significó el socorro inmediato en auxilio de la Corona.

Cuando se trató el tema de las donaciones, el Cabildo se comprometió con dos mil pesos; aparte, los dos alcaldes, Pío Tristán y Francisco

53 Sesión del 10 de enero de 1809, BMA, LAC, n. ${ }^{\circ} 26$. El intendente Salamanca comunicó al Cabildo que el brigadier Goyeneche quiso agradecer personalmente el recibimiento y que «en qualesquiera parte donde se halle recordará con cariño su memoria, la de toda su Patria, y que practicará en su favor cumpliendo con los deberes que contrajo al nacer quanto le sea posible y dependa de su arvitrio». El Cabildo, por su parte, pidió al intendente comunicarle a Goyeneche que Arequipa se honraba de que este fuese hijo suyo.

${ }^{54}$ Manuel Fernández de Arredondo llegó junto con Avilés. Era sobrino del regente de la Real Audiencia de Lima, Manuel Antonio de Arredondo y Pellegrin. En Arequipa se casó con Josefa Barreda Bustamante, prima del brigadier Goyeneche y Barreda, y se dedicó al comercio. Antes de fallecer Avilés, en 1810, fue nombrado capitán de milicias de Arequipa y cumplió un destacado papel en el Cabildo desde 1814 (Wibel 1975: 133-134).

55 Sesión del 30 de septiembre de 1808, BMA, LAC, n. ${ }^{\circ} 26$.

${ }^{56}$ Sesión del 10 de noviembre de 1808, BMA, LAC, n. ${ }^{\circ} 26$.

57 Según Salamanca, desde el 8 de noviembre de 1808, se hicieron seis envíos de las arcas de la intendencia; en la última, el 28 de junio de 1809 , se entregaron 55.352 pesos y $11 / 2$ reales. Agregó que se hicieron erogaciones posteriores que aumentaron esta cifra (Fisher 1968b: 80-81). 
Xavier Cornejo, ofrecieron ochocientos y doscientos pesos respectivamente. El resto de capitulares, nueve en total, donaron quinientos dos pesos; mientras que el regidor decano Rivero y Benavente y el síndico procurador Araníbar se comprometieron en entregar cada uno cien pesos anuales mientras durara el conflicto con Francia. Además, durante la recaudación de donativos se recurrió a exaltar el tradicional fidelismo arequipeño y se les ordenó a los regidores estimular a los donantes por todos los medios que considerasen aptos, al punto que también a las Matronas ilustres se les recordó que dicho título fue conferido por el rey Felipe II a raíz de unos donativos hechos en $1580 .^{58}$

Sobre la ceremonia de juramentación de lealtad al nuevo rey, el Cabildo organizó lo acostumbrado para estos eventos, por lo que siguió lo acordado el 25 de noviembre de 1780, cuando se juró a Carlos IV. No se realizó ninguna innovación, aunque evidentemente la magnitud de la última fue mucho menor, pues «solo se trata de dar pruebas quanto más antes de su fidelidad a tan adorado Monarca». ${ }^{59}$ El evento se organizó en tres lugares: primero en la plaza principal, luego en la de San Francisco y finalmente en la de Santa Marta. Asimismo, se acordó publicar una proclama que comunicara tanto la coronación de Fernando VII como su secuestro: «bien quisieramos evitarlos la una, para que os entregaseis a las delicias de la otra, sin mescla de dolor; pero si teneis derecho por vuestra soveranía, a que se os descubra la favorable [...], también estais obligados, a preguntar por la triste». Tras relatar los sucesos, se criticó la actitud de Carlos IV, entregado ciegamente al Príncipe de la Paz y quien en Bayona reclamó «los derechos perdidos a una Corona, y a un Pueblo, que abandonó». Además, para exaltar el fidelismo arequipeño, se dijo

${ }^{58}$ Sesión del 10 de noviembre de 1808, BMA, LAC, n. ${ }^{\circ} 26$. Avilés no fue considerado dentro de los donantes. En estos montos no se considera el ofrecimiento del intendente de donar la mitad de su salario y que al parecer no fue efectuado. El 22 de noviembre de 1808, el Cabildo eclesiástico entregó cuatro mil pesos y José García Santiago, novecientos pesos (salario de un teniente coronel que pagaría mientras dure la prisión del rey). El 10 de enero del año siguiente, Juan de Goyeneche ofreció tres mil pesos de donación. Ciertamente, existía un espíritu competitivo en este asunto.

${ }^{59}$ Sobre las festividades por la juramentación a Carlos IV, véase «Relación de las fiestas» 1974. 
que, en la «Historia del Perú», este había merecido un digno lugar y, de acuerdo con ello, «estamos levantados en masa. Defendemos nuestra Religión, nuestro Príncipe, y nuestros Derechos». ${ }^{60}$

A pesar de estas muestras obvias de fidelismo, los conflictos entre las autoridades locales no cesaron; al contrario, como parecía costumbre en el siglo XVIII, los ceremoniales se aprovecharon para indisponer a unos y demostrar la autonomía de otros. En la sesión del 7 de noviembre, el intendente Salamanca exhortó a las autoridades a no realizar cambios en la etiqueta porque solo pretendían usurpar los privilegios que tenía su investidura, ya que en la misa celebrada antes de la juramentación, el encargado de dar la paz fue un sacerdote y no un colegial como estaba determinado. ${ }^{61}$ Estos conflictos, sin embargo, y las noticias sobre la situación de la Península en general, quedaron al margen casi de inmediato, tras comunicarse el pronto arribo de Goyeneche y Barreda.

En las elecciones municipales de 1809, ante la renuncia de Goyeneche y Barreda como alcalde de primer voto, venció Tristán y Moscoso. Aunque el regidor decano Rivero y Benavente cumplió las funciones judiciales del alcalde de primer voto, fue Domingo Goyeneche quien presidió las sesiones. Lucas Ureta, por otro lado, fue elegido alcalde de aguas, mientras que Francisco Xavier Cornejo fue procurador general y Araníbar siguió como asesor.

60 «Proclama», BMA, LAC, n. ${ }^{\circ}$ 26, ff. 134-135. Es importante advertir las ideas pactistas en la proclama, tales como la relación entre el rey y el "pueblo». En este sentido, la «Historia del Perú» es la de un reino distinto al resto que conforman la Nación española, pero unida por el rey. Además, cuando se menciona que las noticias fueron transmitidas por Goyeneche, se exalta su participación como comisionado de la Junta: «hermano nuestro, nacido en vuestro suelo, que ha vevido con vosotros unas mismas aguas: bien pronto oyreis de su voca el dulze asento del amor y fidelidad, y por ella al mismo Fernando $70^{\prime}$. Peralta Ruiz señala que Arequipa fue la única ciudad que organizó fiestas públicas tras la juramentación (2010: 105). Sobre las ceremonias, véase el texto titulado «Descripción y papeles relativos a la solemne proclamación del Señor D. Fernando VII, executada el día 3 de diciembre [sic] de 1808. Por la fidelísima ciudad de Arequipa en el Reyno del Perú» en Nieto 1960.

${ }^{61}$ Sesión del 7 de noviembre de 1808, BMA, LAC, n. ${ }^{\circ} 26$. Sobre los conflictos por el ceremonial ver Gallagher 1978: 205-232. 
Ese año, se recibió una importante cantidad de comunicados. Algunos de ellos, provenientes de Buenos Aires, informaban sobre la situación europea. Es importante agregar que Goyeneche y Barreda entregó al Cabildo copias de las cartas que la infanta Carlota Joaquina le dio para que las distribuyese entre las autoridades virreinales. Las cartas no generaron la desconfianza que surgió en otros espacios; una vez más se resaltó el hecho de que un «hijo suyo» fuese el mensajero de tan importante correspondencia. ${ }^{62}$ Del mismo modo, se recibieron oficios enviados por el Consejo Supremo de Indias donde se subrayaba la ilegalidad y nulidad de las abdicaciones de Bayona. En estos documentos se hacían referencias a la soberanía y a la nación. En todos estos casos, en las sesiones del Cabildo solo se leyeron y los capitulares acordaron copiarlos en el libro de provisiones, algunos bajo el título de Monumentos.

En abril llegó la orden del virrey para proceder a reconocer y jurar a la Junta Central —ceremonia que se realizó el 27—y, en junio, la de elegir un diputado para que participe en dicha junta. El 1 de julio se eligieron tres candidatos por votación directa: al deán Saturnino García de Arazuri (por cuatro votos), al alcalde Tristán y Moscoso (también por cuatro votos) y al brigadier Goyeneche y Barreda (por tres votos). Inmediatamente, puestos sus nombres en un cántaro, el niño Francisco Cedillo sacó la cédula con el nombre de Goyeneche y Barreda. ${ }^{63}$ Esta elección evidenció la fortaleza de un sector absolutista monárquico, algunos ubicados estratégicamente en lo más alto de los cargos eclesiásticos, como el deán navarro García de Arazuri.

Durante esta primera fase, el Cabildo transitó entre los acostumbrados temas locales y la nueva coyuntura política que exigía los usuales apoyos económicos. Sin embargo, los efectos de la coyuntura se comenzaron a sentir en la región a la cual estaba vinculada la sociedad arequipeña, lo que implicó un cambio en el control político al interior del Cabildo. Como veremos a continuación, tras los incidentes en Charcas en 1809, el sector al que representaba Tristán y Moscoso se fortaleció y ganó todas las siguientes elecciones.

62 Sesión del 10 de enero de 1809, BMA, LAC, n. ${ }^{\circ} 26$.

${ }^{63}$ Sesión del 1 de julio de 1809, BMA, LAC, n. ${ }^{\circ} 26$. 


\section{SEGUNDA FASE: EL CABILDO DE AREQUIPA Y LA JUNTA TUITIVA DE LA PAZ}

Este periodo inicia en agosto de 1809 con la llegada de las noticias de la formación de la junta paceña, y termina en febrero de 1810, cuando regresaron las tropas arequipeńas que participaron en la pacificación de Charcas y el Cabildo retomó sus tareas cotidianas. La noticia de lo acontecido en La Paz el 16 de julio de 1809 llegó primero a Tacna. Allí, Ramón Ballivián, vecino paceño, escapó con su familia y, el 28 de julio, escribió al marqués de Avilés y al intendente de Arequipa solicitando apoyo contra los rebeldes. ${ }^{64}$ La carta fue recibida el 3 de agosto y, a diferencia de lo acaecido en otros momentos, como con la invasión inglesa a Buenos Aires o la formación de la junta porteña, la noticia afectó inmediatamente a la sociedad arequipeña, al punto que el mismo día se convocó a Cabildo abierto. Los acuerdos a los que llegaron permiten percibir la posición de la élite local. Para empezar, el Cabildo abierto se autodenominó "Junta»; además, se tomaron medidas para reformar el gobierno local, las cuales, pasados algunos días, se rectificaron y justificaron en cartas a Abascal. Una de aquellas medidas trató sobre la soberanía y a quién le correspondía el gobierno de la ciudad.

Reunidos en la sala consistorial y "precedidos» por el marqués de Avilés, autoridades y vecinos escucharon una vez más la lectura de la carta de Ballivián. Luego, el presidente de la sesión dio un discurso «análogo a este negocio" y acordaron auxiliar a la ciudad de La Paz. Se decidió organizar una expedición compuesta por mil quinientos hombres de toda la intendencia, conformada en proporción al tamaño poblacional de los partidos: seiscientos de Arequipa, trescientos de Arica, trescientos de Moquegua, ciento cincuenta de Camaná y ciento cincuenta de Majes. Dada la salud del marqués de Avilés, quien era el militar de mayor graduación en la ciudad, nombraron como comandante de esta tropa al intendente Salamanca. ${ }^{65}$

${ }^{64}$ Carta de Ramón Ballivián a Avilés, «Expediente que trata de las providencias», ASMPA, Legajo 1809-4, ff. 2-4v.

${ }^{65}$ Afirmaron que por que «su edad no lo permite para tan pronta Expedicion; pero ambos cavildos y todos los asistentes a una voz aclamaron y suplicaron a tan digno Gefe que 
Así, inesperadamente, ambos cabildos —el Cabildo, Justicia y Regimiento de la ciudad, y el Cabildo abierto presidido por Avilés - entregaron el mando militar de la expedición al intendente Salamanca, quien había perdido un brazo en 1794 , cuando era capitán de fragata. ${ }^{66}$ De esta manera, los miembros de estas instituciones pretendían deshacerse del intendente y colocar en el gobierno a Avilés; tal vez sospechaban que, por su edad y estado de salud, este no interferiría en los asuntos municipales. Esta medida se tomó conforme a la cédula del Consejo de Indias de 1789, que mandaba que el gobierno político y militar recayese en el oficial de mayor graduación. Pero en 1793, el mismo Cabildo arequipeño protestó contra esta y logró corregir la cédula para que dicho oficial asuma solo el mando militar y, en cambio, las funciones políticas y económicas queden bajo el control del teniente asesor con apoyo de los alcaldes. Esta última corrección de la cédula de 1789 no fue considerada entre las deliberaciones del Cabildo abierto, aun cuando el teniente asesor Antonio Luis Pereyra estuvo presente en la sesión. Nadie mencionó que el gobierno político debía recaer en Pereyra asesorado por los alcaldes. ${ }^{67}$

En su Relación de gobierno, Salamanca indicó que sostuvo una política contra el escándalo para mantener el control de la ciudad y evitar el desorden, incluso más en momentos turbulentos. ${ }^{68}$ Parece ser que este comportamiento continuó durante el Cabildo abierto, porque

en el interin esta al mando de las tropas el Señor Governador se haga cargo de ambos goviernos Político y Militar atendiendo a las circunstancias que nos rodean, y este Señor en fuerza de sus deseos de servir en todo, y siempre a la Patria aceptó el cargo" (Acta de la sesión del Cabildo abierto del 3 de agosto de 1809, «Expediente que trata de las providencias», ASMPA, Legajo 1809-4, ff. 9v-10r).

${ }^{66}$ Fisher 1968a: XI-XII.

${ }^{67} \mathrm{Al}$ parecer, existían diferencias entre el intendente Salamanca y Pereyra, quien se resistió a ir a la Casa de Gobierno para despachar los asuntos judiciales y decidió atenderlos desde su casa, lo que motivó un pedido de Salamanca, en 1811, para que el Consejo de Regencia se pronuncie al respecto. Este finalmente ordenó al teniente asesor concurrir a la Casa de Gobierno para cumplir sus funciones (Fisher 1968b: 27-29). Además, según Goyeneche y Barreda, Pereyra participó del pedido que hicieron otros cinco vecinos para cambiar al intendente (Herreros de Tejada 1923: 456).

${ }^{68}$ Para lograrlo, dijo que acabó con los procesos judiciales más «ruidosos» que venían del gobierno anterior y que tenían lugar en otros partidos (Fisher 1968b: 16-35). 
el intendente minimizó los acuerdos tomados y solo mencionó que se hicieron cuantiosos donativos y se le proclamó como comandante de las tropas, cargo que aceptó. Sobre la intervención de Avilés en el gobierno de la ciudad, Salamanca se limitó a decir que este se "asoció» a su gobierno y le dispensó su admiración por el orden con que administraba la intendencia. ${ }^{69}$

Asimismo, se acordó que Avilés y Salamanca comunicarían directamente lo acontecido al presidente de la Audiencia del Cuzco y al virrey Abascal, y se señaló que a Goyeneche y Barreda le correspondía encargarse del mando de las tropas del sur del virreinato porque era el militar en actividad de mayor graduación. Finalmente, se mandó a redactar una «Proclama relativa al negocio que se trata y se publique todo por Bando». ${ }^{70}$ Ese mismo día, los miembros del Cabildo redactaron un oficio a su similar de La Paz con el objetivo de obtener mayor información sobre los incidentes y conocer las razones del levantamiento. Era importante establecer quiénes eran los insurgentes. Se inició la comunicación expresando asombro por las noticias y rumores que llegaron desde el Alto Perú, pues, a pesar de no conocerse oficialmente los sucesos ocurridos en mayo en Chuquisaca, ${ }^{71}$ los trajinantes debieron difundirlos: "Consternado el Cavildo, Justicia y Regimiento de esta Ciudad con las melancólicas noticias que acaba de resivir por escrito, y de palabra, en que se pinta al vivo la situación amarga y dolorosa de esa; no ha podido escucharlas con indiferencia, ni quisá ha sido dueño de su pensamientos». ${ }^{72}$ El oficio comunicaba a los paceños sobre el Cabildo abierto y la participación de Avilés, y les recordaba la antigua hermandad que unía a ambas ciudades y los títulos de fidelidad ganados durante su resistencia en 1780. Al final, indicaron que el Municipio arequipeño se encontraba persuadido de

\footnotetext{
${ }^{69}$ Fisher 1968b: 33.

${ }^{70}$ Acta de la sesión del Cabildo abierto del 3 de agosto de 1809, «Expediente que trata de las providencias», ASMPA, Legajo 1809-4, f. 10.

${ }^{71}$ Durante los meses de junio y julio, los temas tratados por el Cabildo eran ajenos a la situación de Charcas; véanse sesiones de junio y julio del 1809, BMA, LAC, n. ${ }^{\circ} 26$.

${ }^{72}$ Oficio del Cabildo de Arequipa al de La Paz del 3 de agosto de 1809, «Expediente que trata de las providencias", ASMPA, Legajo 1809-4, ff. 12-13.
} 
que en La Paz no existe «la libertad necesaria para pedir los auxilios que prebienen las Leyes en casos como los que se han retratado", ${ }^{73}$ por lo que dispusieron prestar los necesarios una vez conocidos en detalle los acontecimientos.

Por su parte, el Cabildo de La Paz conocía las inquietudes que despertarían los sucesos del 16 de julio y, luego de establecida la junta y decretado todo lo concerniente al gobierno de la ciudad, acordó enviar representantes y oficios a todas las ciudades que se encontraban en el trayecto del Correo Real hacia Buenos Aires y a las capitales de intendencia del Bajo Perú.

El primer oficio dirigido al Cabildo de Arequipa se envió el 30 de julio y se recibió el 6 de agosto. Salamanca lo leyó el día siguiente y ordenó a su secretario, Juan Manuel de Bracamonte, sacar una copia para su archivo y otra para remitirla a Abascal. Adjunta a dicha representación llegaron escritos sobre los motivos de la formación de la Junta Tuitiva. El Cabildo paceño prometió enviar toda la información necesaria para demostrar que su único objetivo era defender los derechos del secuestrado rey Fernando VII y precaver que Arequipa sea seducida, «de palabra o por escrito", contra las ideas que sostiene La Paz. ${ }^{74}$

Los primeros documentos enviados por el Cabildo paceño fueron la correspondencia reservada entre el virrey del Río de la Plata, Santiago Liniers, el intendente de Potosí, Francisco de Paula Sanz, y el intendente interino de La Paz, Tadeo Fernández Dávila, fechados entre junio y julio de $1809 .{ }^{75}$ En ellos aconsejaban al intendente de La Paz mantenerse atento tras los sucesos del 25 de mayo en La Plata. Sanz le envió copia de las órdenes militares que recibió de Liniers — quien le encargó el mando de las tropas reunidas en Potosí- a Fernández Dávila y le pidió que lo mantenga informado ante cualquier eventualidad que altere el orden en su ciudad. Obviamente, esta información provista por el secretario de la intendencia paceña preocupó a los miembros del Cabildo de La Paz,

${ }^{73} \mathrm{Ib}$.

${ }^{74}$ Oficio del Cabildo de La Paz al de Arequipa del 30 de julio de 1809, «Expediente que trata de las providencias", ASMPA, Legajo 1809-4, ff. 20-22.

75 «Expediente que trata de las providencias», ASMPA, Legajo 1809-4, ff. 17-18. 
quienes señalaron la justicia y legalidad de sus procedimientos frente a la actitud violenta de vecinos como Sanz, un enérgico represor desde la década de 1780 .

Para responder dicho oficio, el Cabildo arequipeño sesionó el 8 de agosto. ${ }^{76}$ En su respuesta se indicó que se había informado al virrey del Perú y al intendente de la ciudad sobre las comunicaciones que mantenían ambos Cabildos y que, «[e]n lo demás Usted sabrá lo que hace, y la responsavilidad de que queda a las legítimas Potestades, si, arrebatado del zelo, ha pasado los límites que todos tenemos, para nuestros procedimientos, aun los más lisitos, sino procura remediarlos en el tiempo». ${ }^{77}$ También convinieron acusar recibo de lo enviado por el Cabildo de La Paz y que «de los Documentos agregados nada resulta en prueba contra los SS. que se expresan», repitiendo una vez más «que por lo demás su señoría el muy ylustre Cabildo de la Paz sabrá lo que hace». ${ }^{78}$ Con esto pretendían dejar claro que no era la intención de los arequipeños entrometerse en los asuntos de otra jurisdicción, porque, a diferencia de la primera comunicación, no se volvió a pedir mayores detalles de lo que sucedía en La Paz.

En aquella misma sesión, las autoridades arequipeñas tomaron ciertas precauciones para evitar el ingreso sin control de noticias. Una de ellas fue advertir «a los camineros, y tamberos desde el instante que se recibieron las noticias de la ciudad de la Paz que indispensablemente den noticia de todo entrante». ${ }^{79}$ Además, comisionaron a dos hombres en los accesos de la ciudad para controlar a las personas y la documentación que provenía del Alto Perú; los gastos de esta guardia fueron afrontados por el intendente y el teniente coronel Pío Tristán.

${ }^{76}$ Acta de la sesión del 8 de agosto de 1809, «Expediente que trata de las providencias», ASMPA, Legajo 1809-4, ff. 23-24.

77 Oficio del Cabildo de Arequipa al de La Paz, 8 de agosto de 1809, «Expediente que trata de las providencias", ASMPA, Legajo 1809-4, f. 25.

${ }^{78}$ Acta de la sesión del 8 de agosto de 1809, «Expediente que trata de las providencias», ASMPA, Legajo 1809-4, f. 23v.

${ }^{79}$ Ib., ff. $23 \mathrm{v}-24 \mathrm{r}$. 
Enterados de que la junta paceña pretendía enviar una diputación a la ciudad, afirmaron que no convenía aceptar la entrada de ningún representante por «no jusgarse necesario». Con ese fin, el síndico procurador del Cabildo, Francisco Xavier Cornejo, fue nombrado para viajar escoltado por seis soldados — costeados por el intendente— hasta los «términos» de la provincia. Allí, Cornejo debía esperar las noticias sobre la supuesta llegada del representante de La Paz y, en caso se compruebe su arribo, entregarle un pliego donde se le indique, "con decoro", lo inútil de su comisión, para así evadir cualquier competencia con el Cabildo paceño. Además, los capitulares arequipeños le indicaron a Cornejo que debía advertir al representante paceño que "por ningún pretesto regrese a esta Provincia durante las actuales circunstancias, como particular ni con qualquier condecoración». ${ }^{80}$ José María de los Santos Rubio y Joaquín de la Riva fueron designados por la Junta Tuitiva como diputados para viajar a Arequipa y Cuzco, respectivamente. Cuando arribaron a Puno, el intendente Manuel Químper les autorizó el paso, pero vigilados por dos hombres ${ }^{81}$ De su comisión no se supo más porque el procurador arequipeño partió con el pliego y seis soldados, pero el diputado nunca llegó a los límites de la provincia. Tras ocho días de espera, Cornejo regresó a la ciudad. ${ }^{82}$

Durante el Cabildo abierto del 3 de agosto, se pidieron donativos para organizar al ejército que auxiliaría a La Paz. El marqués de Avilés fue el primero en donar veinte mil pesos para esta causa, pero el Cabildo dejó en suspenso su aceptación porque se reveló que era el único dinero de Avilés para continuar su viaje. Los miembros del Cabildo sabían que él se encontraba de paso por la ciudad, a pesar de su larga estadía, y, según parece, prefirieron no comprometer tal situación. En cambio, aceptaron la propuesta que Ballivián presentó en su carta: financiar quinientos

\footnotetext{
${ }^{80}$ Ib., f. $23 \mathrm{v}$.

${ }^{81}$ Romero menciona que el comportamiento de Químper era más político, astuto y cauteloso, diferente a quienes como el subdelegado de Chucuito, Tadeo Gárate, pretendían impedir el ingreso de rebeldes e información provenientes de La Paz (1978: 197).

82 Oficio de Francisco Xavier Cornejo al Cabildo de Arequipa del 22 de agosto de 1809, «Expediente que trata de las providencias», ASMPA, Legajo 1809-4, f. 127.
} 
soldados durante treinta días y ponerse al servicio junto con sus hijos. Estas muestras de desprendimiento consiguieron que acordasen reunirse al día siguiente para que «cada vecino concurra a ofrecer por papel, o como le paresca lo que tenga por conveniente por via de donativo». ${ }^{83}$

Propuestas como la de Ballivián eran comunes en momentos como estos. Había quienes hacían donativos en dinero o pagaban el salario de una cantidad determinada de soldados; otros, en cambio, colocaban al servicio de la causa sus personas y las de sus hijos, incluyendo su salario y mantenimiento. Pero también buscaban algún tipo de rédito en estos actos. Como agregó Ballivián, los gastos que se hiciesen podrían ser recuperados tras la victoria con la venta de los bienes y el control de las rentas de los insurgentes.

El 4 de agosto se llevó a cabo la sesión que trató sobre los donativos. ${ }^{84}$ La élite arequipeña ofreció alrededor de 7056 pesos durante esta sesión, sin contar lo ofrecido por Avilés, el intendente y los costos de los servicios personales — sobresalía el ofrecimiento de Goyeneche y Barreda de pagar los gastos de veintiséis soldados encabezados por su hijo Juan Mariano-. Comparativamente, el apoyo económico ante este acontecimiento fue mayor a los mostrados entre 1799 y 1808 , aunque se debe advertir que casi todos los donantes dijeron que las erogaciones serían entregadas cuando se verifique la partida del ejército. No he podido establecer si estos ofrecimientos se cumplieron, pero en la Minerva Peruana se informó que los donativos hechos por Arequipa para auxiliar a La Paz ascendieron a 26.710 pesos y 5 reales, mientras que lo recaudado para apoyar a la Península, hasta el 16 de noviembre de 1809 , fue de 54.318 pesos y 7 reales, sin contar los 2551 pesos y

${ }^{83}$ Acta de la sesión del Cabildo abierto del 3 de agosto de 1809, «Expediente que trata de las providencias», ASMPA, Legajo 1809-4, f. 13.

${ }^{84}$ En la misma sesión se decidió que se comunicaría al virrey Abascal todo lo acordado y se sometería a su parecer lo resuelto, "pues todo lo obrado es solo con el obgeto de que las cosas estén preparadas para aprovechar los instantes, y obrar sin demora si es presiso, y se resuelve el auxilio» (Acta de la sesión del 4 de agosto de 1809, «Expediente que trata de las providencias», ASMPA, Legajo 1809-4, ff. 14-16). 
$7 \frac{1}{2}$ reales que se entregarían anualmente mientras durara la guerra contra los franceses. ${ }^{85}$

Pasados los días, el Cabildo de La Paz comunicó a Avilés que el nuevo virrey del Río de la Plata nombró un nuevo intendente para la ciudad y que, hasta su llegada, se debía mantener el «actual gobierno». Por ello, se pidió que el marqués, el intendente y el Cabildo de Arequipa se empeñaran en el remedio de las «ocurrencias perjudiciales que puedan nacer de los preparativos ostiles que previene contra ella la villa de Puno, y ha puesto en execución, ocupando con gravamen de la demarcación de los respectivos distritos de Copacabana y otros puntos» ${ }^{86}$ Los miembros del Cabildo arequipeño consideraron que las circunstancias habían variado tras esta comunicación, por lo que acordaron escribir al virrey y a Goyeneche y Barreda para intentar evitar «muestras ostiles entre convasallos, hermanos, provincias de un propio soverano", además de gastos que podían utilizarse para sostener la guerra contra Napoleón. ${ }^{87}$

Mas una vez definida la posición del virreinato peruano frente a la Junta Tuitiva, a Arequipa le tocó cumplir con lo ofrecido. Luego de que Goyeneche y Barreda comunicara a Avilés su partida hacia La Paz y expresara sus deseos de contar con el apoyo de las tropas arequipeńas, el Cabildo le escribió a Abascal anunciándole que, tras estas noticias, se había acordado el envío de mil hombres, «pues ya una melancólica experiencia enseña, que aquellos infelices havitantes; aquella desgraciada provincia, solo con fuertes críticos pueden habrir sus ojos facinados». ${ }^{88}$

La oficialidad alrededor del brigadier Goyeneche y Barreda era criolla y provenía, básicamente, del Cuzco y Arequipa. Sus edecanes fueron el coronel Pablo Astete, el teniente coronel Mariano Campero, el capitán Juan Mariano Goyeneche y el capitán José Mariano de Cossío.

${ }^{85}$ Minerva Peruana, 17 de mayo de 1810; esta cifra es similar a la que da el intendente Salamanca (Fisher 1968b: 78-81).

${ }^{86}$ Sesión del 22 de septiembre de 1809 , BMA, LAC, n. ${ }^{\circ} 26$. ${ }^{87} \mathrm{Ib}$.

${ }^{88}$ Copia del oficio del Cabildo de Arequipa al virrey Abascal del 6 de octubre de 1809, «Expediente que trata de las providencias», ASMPA, Legajo 1809-4, ff. 149-150. 
Los dos primeros eran miembros de la élite criolla cuzqueña, y los otros dos, hijos de poderosos comerciantes arequipeños. Los edecanes de Juan Ramírez fueron los capitanes Pedro Barreda, hijastro de Domingo Tristán, Miguel Carazas y el marqués de Cochán. Por debajo de ellos se encontraba el teniente coronel Pío Tristán, quien tenía de ayudante al teniente Francisco Vidal, mientras que el auditor de guerra fue Pedro López Segovia, asesor de la Audiencia del Cuzco. ${ }^{89}$ Con ellos, autorizado por el Cabildo, participó el alcalde de segunda nominación de Arequipa, Tristán y Moscoso. A este último, en 1809, le tocó ser el vínculo entre esta corporación y el ejército pacificador del Alto Perú. La documentación intercambiada con Goyeneche y el Cabildo de La Paz fue copiada por él mismo y enviada a su ciudad.

Las noticias de la victoria de Goyeneche y Barreda del 25 de octubre recién se recibieron a fines del mes de noviembre. El Cabildo de La Paz remitió un oficio fechado el 15 de noviembre, donde se informaba «la plausible noticia» del triunfo de Tristán y Moscoso y Pedro Barreda en Yungas, y de la opresión que sufrió aquella ciudad por obra de «algunos pocos malvados». Adjunto a este documento, Tristán y Moscoso mandó copias de sus cartas dirigidas a Goyeneche y Barreda donde dio alcance de sus acciones. Con estas noticias se acordó que no era necesario continuar manteniendo al soldado que vigilaba el camino hacia la sierra. ${ }^{90}$

El mismo día que los arequipeños conocieron la victoria sobre los insurgentes, Goyeneche y Barreda les comunicó el nombramiento de Tristán y Moscoso como comandante de la tropa pacificadora de Yungas, y de Pedro Barreda como su segundo al mando. Dicha tropa estuvo conformada por quinientos soldados, todos ellos de los regimientos provenientes de la intendencia de Arequipa. En diciembre, Goyeneche y Barreda comunicó a Avilés la pacificación total de La Paz. ${ }^{91}$

La reacción del Cabildo tras la formación de la Junta Tuitiva se puede calificar como fidelista, pero debemos entenderla sobre todo como la defensa de sus propios intereses económicos; no olvidemos que Arequipa

\footnotetext{
${ }^{89}$ Herreros de Tejada 1923: 200-201.

${ }^{90}$ Sesión del 21 de noviembre de 1809 , BMA, LAC, n. 26.

${ }^{91}$ Sesión del 20 de diciembre de 1809, BMA, LAC, n. ${ }^{\circ} 26$.
} 
era uno de los principales centros proveedores de las minas altoperuanas. A diferencia de lo planteado por Brian Hamnett, quien señala que la posterior reincorporación de Guayaquil, Charcas y Chile a la jurisdicción política del virreinato peruano fue básicamente alentada por la élite limeña, ${ }^{92}$ considero que, ante las dificultades de comunicación con Lima, el virrey dejó en manos de las élites locales la resolución de los conflictos regionales y, así, les permitió cierto grado de autonomía.

Las comunicaciones leídas y discutidas en la sala consistorial terminaron por politizar el ambiente municipal arequipeño. Ninguna coyuntura anterior generó la cantidad de sesiones de 1809. Ni siquiera las noticias de la guerra contra los ingleses, a fines del siglo XVIII, o las invasiones a Buenos Aires, o la crisis monárquica de 1808, conllevaron un aumento en las reuniones del Cabildo. ${ }^{93}$ Como consecuencia, la producción y la circulación de documentación se vieron incrementadas. Las autoridades intentaron mantener el control sobre la información para evitar alteraciones en la ciudad.

\section{TERCERA FASE: DE LA TENSA CALMA AL ESTALLIDO REVOLUCIONARIO}

En enero de 1810, regresó la calma al Cabildo arequipeño, que volvió a tratar temas cotidianos. En julio de aquel año, sin embargo, se recibieron las primeras noticias de lo acaecido en mayo en Buenos Aires y, así, se inició una nueva coyuntura política y militar marcada por la formación de las cortes en la Península y de las juntas en la América española. Las repercusiones del movimiento porteño en el Alto Perú, afectaron directamente a Arequipa.

Durante la fase anterior, la presencia de Avilés constituyó el equilibrio que el Cabildo arequipeño necesitaba para restarle poder al intendente. Por tal razón, en la sesión del 26 de octubre de 1809, al tanto de que el marqués de Avilés «trata de ausentarse de esta ciudad y privarla de la posesión de sus virtudes y consejo; y deseando este cuerpo su permanencia»,

\footnotetext{
${ }^{92}$ Hamnett 2000: 14-16.

${ }^{93}$ De 1800 a 1808 el promedio oscila en 2,4 sesiones mensuales, y de 1809 a 1812 sesionaron en promedio cuatro veces mensuales.
} 
acordaron enviarle un oficio suplicatorio para evitar su partida. Pero su retiro de la ciudad era inminente, y así lo hizo saber Avilés. El Cabildo incluso llegó a pedir la intervención de Abascal para disuadirlo, pero este dijo que nada podía hacer, pues no podía contrariar una orden real, a pesar de lo provechosa que resultaba la estadía de Avilés en Arequipa. ${ }^{94}$

El 20 de diciembre, Goyeneche y Barreda informó al Cabildo que parte de la tropa, encabezada por el coronel Tristán y Moscoso, retornaba a Arequipa y que con ella enviaba una de las banderas capturadas: «Para que conserbándola mi ylustre Patria sirva de modelo y estímulo a la posteridad que desde ahora debe aumentar sus desbelos para adquirir nuebos timbres que aumenten la grande gloria y leal honor que tiene acreditada». ${ }^{95}$ La bandera fue colocada en la capilla de Nuestra Señora del Consuelo, virgen de la cual la familia Goyeneche era devota.

En la sesión celebrada el mismo día se leyó una real orden del 3 de mayo de 1809 que informaba sobre el nombramiento del marqués de Astorga como nuevo vicepresidente de la Junta Suprema Gubernativa, tras la muerte del Conde de Floridablanca; además de un real decreto del 25 de mayo de 1809 «sobre Cortes». Pero toda la atención del Cabildo estaba puesta en el retorno de sus milicias. Acordaron que «se de un refresco de carnes y verduras a las tropas, y una comida decente al Comandante y oficialidad». ${ }^{96}$ La compañía de granaderos sería recibida en la plaza. Se invitó a los músicos para que tocasen en la bienvenida, se publicó un bando y se ordenó iluminar la ciudad en la noche; doscientos pesos se destinaron para estos gastos. ${ }^{97}$ Además, tal como se acostumbraba, una comitiva dirigida por el intendente salió a recibirlos hasta el pueblo de Cangallo, ubicado en el camino hacia el Alto Perú.

${ }^{94}$ Expediente sobre la partida de Avilés de Arequipa ASMPA, Legajo 1809-4. La respuesta de Abascal es del 27 de noviembre.

${ }^{95}$ Oficio de José Manuel de Goyeneche y Barreda al intendente y al Cabildo de Arequipa, 9 de diciembre de 1809, "Expediente que trata de las providencias», ASMPA, Legajo 1809-4, f. 207.

${ }^{96}$ Sesión del 20 de diciembre de 1809, BMA, LAC, n. ${ }^{\circ} 26$.

${ }^{97} \mathrm{Ib}$. 
El trato que los vecinos dieron a sus milicias contrasta con el dado a un regimiento real proveniente de Lima. Días antes, el intendente informó de su llegada "para reclutar gente»; la ciudad debía darles alojamiento y cuartel. ${ }^{98}$ Poco después, el comandante de infantería se quejó porque los trescientos hombres encargados de la guarnición de la ciudad no tenían el espacio adecuado en el lugar que se les había destinado. ${ }^{99}$ El Cabildo acordó pedir al gobernador eclesiástico el edificio del colegio de los expulsados jesuitas y, a cambio, le entregaría el tambo donde estaban las tropas para que aproveche sus rentas. ${ }^{100}$ Sin embargo, el gobernador se negó a proporcionar el local y protestó ante Abascal por el «despojo que dice haversele hecho de uno de los principales departamentos de la Casa de Misedicordia para que lo ocupe un troso de la tropa». ${ }^{101}$ Recién el 22 de febrero de 1810 alcanzaron un acuerdo y el gobernador eclesiástico aceptó prestar las piezas del palacio del Buen Retiro, ubicada en los límites de la ciudad, para las tropas triunfantes que llegaron del Alto Perú. ${ }^{102} \mathrm{El}$ primer contingente al mando de Tristán y Moscoso arribó a finales de diciembre, pero el Ayuntamiento esperó la presencia de toda la tropa para cumplir con la celebración.

Entretanto, el 31 de diciembre de 1809, se eligieron nuevas autoridades municipales. Increíblemente en dicho proceso no se eligió alcalde de primer voto, sino que de manera automática el cargo recayó en Tristán y Moscoso, quien, al día siguiente, juramentó. Al parecer, fue un acuerdo interno entre los electores y el intendente, ya que no figura ninguna referencia ni documento que indique por qué Tristán y Moscoso juró como alcalde sin haber sido elegido. Ni siquiera durante el gobierno de Álvarez y Jiménez, cuando funcionó un mecanismo bienal para elegir alcaldes, se obvió la elección. En todo caso, esto confirma la influencia que Tristán y Moscoso ganó dentro del Cabildo.

98 Sesión del 18 de diciembre de 1809, BMA, LAC, n. 26.

99 Oficio del Comandante Felipe de Olazábal al Cabildo de Arequipa del 28 de diciembre de 1809, ASMPA, Legajo 1809-4.

${ }^{100}$ Sesión del 30 de diciembre de 1809, BMA, LAC, n. ${ }^{\circ} 26$.

${ }^{101}$ Sesión del 10 de marzo de 1810, BMA, LAC, n. ${ }^{\circ} 26$.

${ }^{102}$ Sesión del 22 de febrero de 1810, BMA, LAC, n. ${ }^{\circ} 26$. 
El 26 de febrero, ingresó a la ciudad el resto de tropa al mando del coronel Mateo de Cossío, por lo que el «Representante de la Patria» —-denominación que dio Salamanca al Cabildo— procedió a organizar las celebraciones. ${ }^{103}$ Como parte de ellas, el 10 de marzo, el intendente remitió un retrato de Goyeneche y Barreda para que sea expuesto en la sala capitular. ${ }^{104} \mathrm{El}$ virrey, por otro lado, escribió al Cabildo arequipeño para agradecerle su apoyo y ordenar que, en nombre del rey, agradezca a los oficiales. ${ }^{105}$ Esta medida se cumplió de inmediato con la entrega de tres oficios de agradecimiento: uno al coronel Tristán y Moscoso, ${ }^{106}$ otro al coronel del regimiento de caballería Mateo de Cossío ${ }^{107}$ y el último al comandante del regimiento de artillería Felipe de Olazábal; ${ }^{108}$ en los tres casos se solicitó hacer extensivo el saludo a toda la tropa.

Ni las noticias sobre la creación del Consejo de España e Indias ni los anuncios de la derrota española sufrida en Zaragoza alteraron los asuntos tratados en las sesiones. ${ }^{109}$ Los temas del gobierno local, como la reaparición de la epidemia de rabia o el pronto arribo del nuevo obispo La Encina, ${ }^{110}$ se postergaron por los de orden central, tales como los pedimentos del virrey para levantar nuevos donativos. Incluso el aviso sobre las alteraciones en Buenos Aires pareció ser tratado de manera

${ }^{103}$ Oficio de Salamanca al Cabildo de Arequipa del 26 de febrero de 1810, «Expediente que trata de las providencias", ASMPA, Legajo 1809-4, f. 214.

${ }^{104}$ Oficio de Salamanca al Cabildo de Arequipa del 8 de marzo de 1810, «Expediente que trata de las providencias», ASMPA, Legajo 1809-4, f. 222.

${ }^{105}$ Oficio del virrey Abascal al Cabildo de Arequipa del 22 de marzo de 1810, «Expediente que trata de las providencias», ASMPA, Legajo 1809-4, f. 224.

${ }^{106}$ Copia del oficio del Cabildo de Arequipa a Domingo Tristán del 9 de abril de 1810, «Expediente que trata de las providencias», ASMPA, Legajo 1809-4, f. 225.

${ }^{107}$ Copia del oficio del Cabildo de Arequipa a Mateo de Cossío del 13 de abril de 1810, «Expediente que trata de las providencias», ASMPA, Legajo 1809-4, f. 225v.

${ }^{108}$ Copia del oficio del Cabildo de Arequipa a Felipe de Olazával del 13 de abril de 1810, «Expediente que trata de las providencias», ASMPA, Legajo 1809-4, f. 226.

${ }^{109}$ Copia del oficio de Martín de Garay, fechado en el Real Alcázar de Sevilla del 31 de julio de 1809, recibido por el Cabildo de Arequipa en marzo de 1810, «Expediente que trata de las providencias», ASMPA, Legajo 1809-4, ff. 218-221.

${ }^{110}$ Sobre la posición política del obispo La Encina en esta coyuntura, véase Carrión Ordoñez 1969-1971; Bermejo 1960; y Gallagher 1978: 233-258. 
marginal en un principio. Solo tras los informes del avance de las tropas porteñas y las luchas en Córdoba y Tucumán, volvieron a alterar la frecuencia en las sesiones y los acuerdos del Cabildo. ${ }^{111}$ Una vez más, el Alto Perú estaba en conflicto y, con este, los intereses económicos, sociales y políticos de la ciudad.

En la sesión del 12 de julio de 1810, Salamanca informó haber recibido un oficio del intendente de Cochabamba en el que le comunicaba lo sucedido en mayo en Buenos Aires y se sujetaba a la autoridad del virrey peruano. En la misma sesión, el intendente advirtió lo siguiente:

Corren algunos papeles consernientes a lo anterior los que son subersibos en el todo, que aun que está sumamente satisfecho de la lealtad de sus probincianos, pero que deviendo atajarse tan venenosa lectura que siempre es perjudicial que le parecía debían recogerse para que no sirculen, practicándose sin ruido, y por medio de arvitrios prudentes, como tomarlos de cualesquiera que se sepa los tiene, y recogerlos así estos como todos los que traten en igual forma de esta materia. ${ }^{112}$

Esta medida fue aprobada por el Cabildo. Pero una vez conocido el arresto del virrey rioplatense, del obispo y del gobernador de Córdoba, se decidió esperar antes que solicitar información u organizar los auxilios tal como lo hicieron en $1809 .{ }^{113}$

Enterados los miembros del Cabildo arequipeño que el intendente — siguiendo instrucciones del virrey Abascal—ordenó que quinientos soldados arequipeños fuesen enviados a fortalecer los ejércitos reales para que marchen en defensa de la Audiencia de Charcas, decidieron responder que, según señalaban las Leyes de Indias, se debía acordar con esta corporación el envío de sus tropas; ${ }^{114}$ sin embargo, conscientes de la situación actual y conocedores de las órdenes del virrey, no podían

${ }^{111}$ Sesión del 6 de septiembre de 1810, BMA, LAC, n. 26.

${ }^{112}$ Sesión del 12 de julio de 1810, BMA, LAC, n. ${ }^{\circ} 26$.

${ }^{113}$ Acordaron «se espere para mejor demostrar los sentimientos de que se halla revestido el Cuerpo, que siempre, quando el lance no sea instantáneamente urgente, esta pronto a [agregado superior 'esperar y'] ovedecer las ordenes» del virrey (Sesión del 6 de septiembre de 1810, BMA, LAC, n. $\left.{ }^{\circ} 26\right)$.

${ }^{114}$ Recopilación de leyes de los reinos de las Indias 1681: Libro III, Título IV, Ley III. 
más que aceptarlas. De todas formas se advirtió que «el soldado es tan necesario en la constitución actual como lo es el alimento más presiso y de primera deducción»; ${ }^{115}$ en ese sentido, se temía la posibilidad de ser atacados en alguno de los puertos inmediatos como Arica, Quilca o alguna caleta. Asimismo, el Cabildo pidió se destine la mitad del contingente para la defensa de la ciudad: «Que es lo mismo que desir ciento porque han salido ciento y sincuenta por delante, y doscientos y sincuenta a los partidos de los regimientos que incluye sin perder la atención que encarga la Ley de quedar las armas y municiones necesaria». ${ }^{116}$ El cuerpo municipal se hacía más reacio a facilitar tropas y armas sin antes asegurar los precisos para su defensa. Esta posición se endureció al punto de negar el envío de pertrechos al ejército de Goyeneche y Barreda, ${ }^{117}$ quien más de una vez tuvo que escribir personalmente al Cabildo para solicitar alimentos y demás productos para sus tropas. ${ }^{118}$

La convocatoria a Cortes también fue un tema soslayado por el Cabildo. El 9 de agosto se recibieron las instrucciones para su elección y, el 29 de mismo mes, se indica en el libro de actas que dicha elección no se llevó a cabo por ausencia de sus miembros. Recién el 22 de septiembre se procedió con la elección, pero ninguno de los candidatos aceptó su denominación. No fue sino hasta diciembre de 1810 que, presionados por el virrey, se eligió a Araníbar como diputado por Arequipa. ${ }^{119}$

Parecía que a los capitulares les preocupaba más la falta de acompañamiento durante el paseo del pendón real en las celebraciones del 15 de agosto:

Solo uno de los vecinos de la ciudad el teniente de ynfanteria don Ventura Berenguel asistió acompañando al cuerpo, la misma falta que por lo común se observa en todos los años, haciendo despreciable la función en cierto modo regia, que debe acordar la gloria de la conquista, y avivar el omenaje que justamente se debe tributar a la soberanía. ${ }^{120}$

${ }^{115}$ Sesión del 14 de septiembre de 1810, BMA, LAC, n. ${ }^{\circ} 26$.

${ }^{116}$ Sesión del 14 de septiembre de 1810, BMA, LAC, n. ${ }^{\circ} 26$.

117 Sesión del 27 de noviembre de 1810, BMA, LAC, n. ${ }^{\circ} 26$.

${ }^{118}$ Sesión del 17 de noviembre de 1810, BMA, LAC, n. ${ }^{\circ} 26$.

${ }^{119}$ Sobre esta coyuntura, véase Gallagher 1978: 242-244.

${ }^{120}$ Sesión del 16 de agosto de 1810, BMA, LAC, n. ${ }^{\circ} 26$. 
$\mathrm{Ni}$ el convite pagado por el alférez real, ni el bando publicado durante dos días, ni la multa por inasistencia doblegaron la indiferencia del vecindario. ${ }^{121}$

Posiblemente, lo que más incomodó a la élite arequipeña fue el incremento de los gastos públicos y las donaciones, motivados por la crisis. El 18 de agosto de 1810, la llegada desde La Paz de Carlos Peńaranda, reo comprometido con el levantamiento de 1809 y desterrado a Lima por reincidente, obligó al Cabildo a entregar veinticinco pesos para su alimentación; por ello, «no pudiendo dejar de exponer el cuerpo los inconvenientes que resultan de esta continua remición de reos", se pidió al virrey prescribir las normas para el modo de traslado de reos. ${ }^{122}$

La inestabilidad política obligó — una vez más—a militarizar el Alto Perú y exigió auxilios económicos y militares a todos los territorios del sur del virreinato peruano. Tras esta situación, y ante una nueva coyuntura constitucionalista, el poder de negociación del Cabildo arequipeño se acrecentó y posibilitó, así, entre 1811 a 1814, el ingreso al Cabildo de personas que defendieron una posición autonomista y utilizaron ideas liberales y constitucionales para limitar la autoridad virreinal en Arequipa.

\section{PALABRAS FINALES}

El 16 de noviembre de 1818, mediante real cédula expedida en Madrid, Fernando VII concedió al Cabildo de Arequipa el tratamiento de «Excelencia» y el uso de uniformes a sus regidores, ${ }^{123}$ debido a su participación en la defensa de la Corona y contra los insurgentes del Alto Perú en 1809. Si bien esta medida tenía un carácter simbólico y se le concedió nueve años después de los sucesos, fue precedida por otros beneficios políticos y económicos que recibió la élite arequipeña; estas fueron razones suficientes para mantener su apoyo al sistema monárquico.

${ }^{121} \mathrm{Ib}$.

${ }^{122}$ Sesión del 18 de agosto de 1810, BMA, LAC, n. ${ }^{\circ} 26$.

${ }^{123}$ El uniforme consistía en «casaca y calzón de terciopelo negro, cuello, vueltas y chupa de lana, medias de seda, espadín y hebillas de oro y bastón» (Pereira y Ruiz 1983). 
Junto con los cargos y privilegios otorgados — sin mencionar los ascensos militares entregados a la oficialidad arequipeña-, la crisis iniciada en 1808 posibilitó dos hechos importantes. Primero, la anexión de Charcas al virreinato peruano por decreto del virrey Abascal del 13 de julio de 1810. De esta forma, los destinos políticos del Alto y el Bajo Perú quedaron una vez más unidos bajo un mismo gobierno, lo que en apariencia favorecía a los hacendados y comerciantes arequipeños. Y segundo, los grandes beneficios que el empoderado sector comercial obtuvo de esta situación. Esto se debió tanto al contrabando existente - cuya magnitud es mencionada en las memorias de Goyeneche y Barreda, en la Relación de gobierno de Salamanca y en las observaciones de viajeros y documentos oficiales-, como a su papel de abastecedores del ejército español acantonado en estos territorios.

El virrey Abascal juzgó que las victorias de Manuel Arredondo y Mioño, en el norte del virreinato peruano, y de Goyeneche y Barreda, en el sur, fueron el resultado de su política de concordia entre peninsulares y criollos. En adelante, dejó en manos de las élites locales la represión de los rebeldes, sin saber que esta determinación fortaleció aún más la autonomía de los gobiernos locales. El fidelismo con que respondieron las ciudades del Bajo Perú fue el mecanismo que utilizaron para defender sus privilegios como corporación y obtener nuevos, al mismo tiempo que protegían sus bienes e intereses particulares.

En Arequipa, la élite utilizó esta vía para consolidar su poder político $y$, tras los sucesos de 1809, obtuvo el control de la intendencia a través de uno de sus miembros. La presencia del marqués Gabriel de Avilés en la ciudad, por su edad, no implicó un riesgo a los proyectos autonomistas; al contrario, fue utilizado para restarle poder al intendente Salamanca quien, a pesar de haberse casado con una dama arequipeña, Petronila O’Phelan y Recabarren, no fue considerado miembro de la élite local ni vinculado por intereses a esta. Esto no significa, sin embargo, la ausencia de posiciones distintas dentro de la élite. De hecho, en momentos de crisis, esta mostró cierto grado de unidad en cuanto a la defensa de su autonomía: todas las posiciones apuntaron a la defensa del control de la economía y de las instituciones de gobierno locales, y de la seguridad de 
la ciudad que gobernaban y donde tenían sus familias y negocios - lo que les permitía conservar su posición dominante-. Así, el grupo radical alrededor de Tristán y Moscoso y los Rivero solicitó reiteradamente a la Corona la incorporación de la intendencia arequipeña a la jurisdicción de la Audiencia del Cuzco, o la creación de una nueva Audiencia con sede en su ciudad. Este pedido se hacía desde fines del siglo XVIII, luego de las grandes rebeliones indígenas de la década de 1780 .

Durante la crisis monárquica, la relación entre el virrey y los Cabildos fue delicada. Al conocer Abascal que los «centros de operaciones» de las juntas eran los Cabildos, ${ }^{124}$ se manejó con más recelo hacia estos. Por tal razón, el único tenor de sus comunicaciones con el de Arequipa fue de gratitud. En cambio, los oficios enviados por el Cabildo a Abascal intentaban justificar su accionar; así, en uno señaló que «quizá nuestro zelo habrá propasado los limites devidos; pero todo lo remediara Vuestra Excelencia, librando las ordenes que correspondan». ${ }^{125}$ Luego, se agregó que todo lo actuado era de conformidad con Avilés; acaso los miembros del Cabildo no se fiaron de la información que remitía el intendente Salamanca a Lima, lo cual solo aumentaba el estado de incertidumbre que se vivía.

Aunque Manuel de Mendiburu supuso que la situación altoperuana de 1809 fue la excusa que utilizó Abascal para "hacerse árbitro» de los destinos de Charcas, ${ }^{126}$ considero que el virrey confió en las decisiones de Goyeneche y Barreda y en las informaciones de Avilés. A las noticias sobre la insurgencia charqueńa se sumaron las del levantamiento ocurrido en agosto en Quito, ${ }^{127}$ lo que implicó gastos adicionales que solo eran posible sufragar mediante préstamos y donaciones de los comerciantes

${ }^{124}$ O’Phelan Godoy 1988: 75.

125 Oficio del Cabildo de Arequipa al Virrey Abascal del 8 de agosto de 1809, «Expediente que trata de las providencias", ASMPA, Legajo 1809-4, ff. 26-27.

${ }^{126}$ Mendiburu 1874-1890, I: 47.

${ }^{127}$ En los libros de actas del Cabildo no aparece ninguna mención a la formación de la junta de Quito; tampoco en los expedientes aquí estudiados. Al parecer, Abascal evitó difundir noticias de uno y otro lado, por lo que las comunicaciones entre el norte y el sur del virreinato fueron siempre limitadas. A pesar de esto, es posible afirmar con seguridad que circularon rumores sobre lo acontecido en el norte. Tal es el caso de Felipe Rocha en el Cuzco, quien fue acusado por estar en comunicación con la Junta Tuitiva de la Paz y 
limeños, con el apoyo de las élites norteñas. Así, los conflictos por dos frentes, sin contar los que mantenía con el Cabildo limeño, obligaron a Abascal a delegar la dirección militar. Aunque Scarlett O’Phelan Godoy afirma que las represiones contra las juntas de Quito y La Paz fueron comandadas por miembros de la élite capitalina, ${ }^{128}$ solo la expedición de Manuel Arredondo y Miońo, enviada a Quito, puede ser considerada como tal —aun así, esta contó con el importante apoyo de las élites de Popayán, Pasto y Cuenca-. En cambio, el contingente comandado por el coronel Juan Ramírez, enviado al sur, estuvo bajo las órdenes de Goyeneche y Barreda, y sus edecanes — como el capitán arequipeño Pedro Barreda - fueron miembros de la élite sureña.

La incertidumbre e inseguridad acrecentadas por la crisis de la monarquía desde 1808 no fueron ajenas a la población arequipeña. Y su respuesta natural ante estas circunstancias fue la de cerrar la ciudad, única realidad política, económica y social tangible en momentos convulsos, a cualquier intervención externa, por temor a desatar las contradicciones que había dentro de la sociedad local.

Las reformas municipales emprendidas por los intendentes fortalecieron económicamente al Cabildo y los serios conflictos entre las autoridades locales posibilitaron su politización. El inicio de la crisis de la monarquía agravó las pugnas, como lo evidencian las discusiones que aparecen en los libros de actas y en los procesos administrativos y judiciales seguidos por el Cabildo. Durante el periodo de 1811-1814, el ayuntamiento constitucional intentó demostrar su fortaleza política al oponerse a los gobernadores superiores e inclusive algunos de sus miembros contrariaron a Abascal. Pero esto es materia de futuros estudios.

noticiar sobre la situación quiteña; declararon a su favor el cura José Díaz Feyjoo, Juan Corbacho, Miguel Bonifacio Araníbar, entre otros (Cornejo Bouroncle 1955: 209-210). ${ }^{128}$ O’Phelan Godoy 1988. 


\section{BIBLIOGRAFÍA}

Abascal, José Fernando de. 1944. Memoria de Gobierno. Edición preparada por Vicente Rodríguez Casado y José Antonio Calderón Quijano. Sevilla: Escuela de Estudios Hispano-Americanos de la Universidad de Sevilla, 2 vols.

Bermejo, Vladimiro. 1960. «El Illmo. Señor Luis Gonzaga de la Encina XVIII Obispo de Arequipa y el fidelismo del clero arequipeño». En Actas del Simposio La Causa de la Emancipación del Perú. Testimonios de la época precursora 17801820. Lima: Pontificia Universidad Católica del Perú, 355-416.

Carrión Ordoñez, Enrique. 1969-1971. «Pereira y el Perú». Boletín del Instituto Riva-Agüero. Núm. 8: 15-123.

Chalco Pacheco, Genaro Edgar. 1991. El Cabildo de Arequipa en el siglo XVI. Tesis para optar el grado de Bachiller en Historia. Arequipa: Universidad Nacional de San Agustín.

. 1993. Los Regidores Perpetuos del Cabildo de Arequipa. Un grupo de poder (Siglo XVI). Tesis para optar el título de Licenciado en Historia. Arequipa: Universidad Nacional de San Agustín.

Chambers, Sarah C. 2003. De súbditos a ciudadanos: honor, género y politica en Arequipa. 1780-1854. Lima: Red para el desarrollo de las Ciencias Sociales en el Perú.

Chiaramonte, José Carlos. 2004. Nación y Estado en Iberoamérica. El lenguaje politico en tiempos de las independencias. Buenos Aires: Sudamericana.

Chiaramonti, Gabriella. 2005. Ciudadanía y representación en el Perú (1808-1860). Los itinerarios de la soberanía. Lima: Universidad Nacional Mayor de San Marcos, Segretariato Europeo per le Pubblicazioni Scientifiche y Oficina Nacional de Procesos Electorales.

Chust, Manuel. 2007. «Un bienio trascendental: 1808-1810». En Chust, Manuel (coord.). 1808. La eclosión juntera en el mundo hispano. México, D. F.: Fondo de Cultura Económica y Colegio de México, 11-50.

Cornejo Bouroncle, Jorge. 1955. «Pumacahua. La revolución del Cuzco de 1814». Revista del Archivo Histórico del Cuzco. Año 6, núm. 6: 5-434.

Cúneo Vidal, Rómulo. 1978. «Historia de las insurrecciones de Tacna por la independencia del Perú. 1811-1813». En Obras Completas. Tomo 4. Precursores y Mártires de la Independencia del Perú. Vol. VI. Lima: Editor Ignacio Prado Pastor, 151-403.

Echenique, José Rufino. 1952. Memorias para la historia del Perú (1808-1878). Lima: Editorial Huascarán, 2 vols.

Fisher, John. 1968a. «Prólogo». En Arequipa, 1796-1811. La Relación del Gobierno del Intendente Salamanca. Lima: Universidad Nacional Mayor de San Marcos, I-XXV. 
(ed.). 1968b. Arequipa, 1796-1811. La Relación del Gobierno del Intendente

Salamanca. Lima: Universidad Nacional Mayor de San Marcos.

1981. Gobierno y sociedad en el Perú colonial: el régimen de las intendencias,

1784-1814. Lima: Pontificia Universidad Católica del Perú.

Gallagher, Mary. 1978. Imperial reform and the struggle for regional self-determination: bishop, intendants and creole elites in Arequipa, Peru (1784-1816). Tesis de doctorado. Nueva York: City University of New York.

Hamnett, Brian R. 2000. La politica contrarrevolucionaria del Virrey Abascal: Perú, 1806-1816. Lima: Instituto de Estudios Peruanos.

Herreros de Tejada, Luis. 1923. El teniente general D. José Manuel de Goyeneche, primer conde de Guaqui. Barcelona: Talleres de Oliva y Vilanova.

Lira, Juan Agustín. 1834. Exposición que hace el ciudadano [...] de su conducta pública desde el año 1815 hasta fin de septiembre de 1834. Lima: Imprenta y Litografía por Correa.

Lynch, John. 2008. Las revoluciones hispanoamericanas, 1808-1826. Barcelona: Ariel. Martínez, Santiago. 1946. Alcaldes de Arequipa desde 1539 a 1946. Arequipa: [s. e.]. Mendiburu, Manuel de. 1874-1890. Diccionario histórico-biográfico del Perú. Lima: Imprenta de J. Francisco Solís, 8 vols.

Nieto Vélez, Armando. 1960. Contribución a la historia del fidelismo en el Perú (18081810). Lima: Pontificia Universidad Católica del Perú e Instituto Riva-Agüero.

O’Phelan Godoy, Scarlett. 1988. «Por el Rey, Religión y la Patria. Las juntas de gobierno de 1809 en La Paz y Quito». Boletín del Instituto Francés de Estudios Andinos. Tomo 17, núm. 2: 61-80.

Peralta Ruiz, Víctor. 2002. En defensa de la autoridad. Política y cultura bajo el gobierno del virrey Abascal. Perú, 1806-1816. Madrid: Consejo Superior de Investigaciones Científicas.

2007. «Entre la fidelidad y la incertidumbre. El virreinato del Perú entre 1808 y 1810». En Chust, Manuel (coord.). 1808. La eclosión juntera en el mundo hispano. México, D. F.: Fondo de Cultura Económica y Colegio de México, 138-161.

2010. La independencia y la cultura política peruana (1808-1821). Lima: Instituto de Estudios Peruanos y Fundación Manuel J. Bustamante de la Fuente. Pereira y Ruiz, Antonio. 1983. "Noticia de la Muy Noble y Muy Leal Ciudad de Arequipa en los Reynos del Perú». En Carrión, Enrique. La lengua en un texto de la Ilustración. Edición y estudio filológico de la Noticia de Arequipa de Antonio Pereira y Ruiz. Lima: Pontificia Universidad Católica del Perú.

Recopilación de leyes de los reinos de las Indias. 1681. Madrid: Julián de Paredes. http://fondosdigitales.us.es/fondos/libros/752/14/recopilacionde-leyes-de-los-reynos-de-las-indias/

«Relación de las fiestas que la ciudad de Arequipa celebró con motivo de la exaltación al trono de Carlos IV». 1974. En Ugarte Chamorro, Guillermo (ed.). 
Colección Documental de la Independencia del Perú. Tomo XXV: El teatro en la Independencia. Lima: Comisión Nacional del Sesquicentenario de la Independencia del Perú, vol. I, 51-117.

Rojas Ingunza, Ernesto. 2008. «A propósito de 1808: el clero arequipeño y el liberalismo español». Anuario de Historia de la Iglesia. Núm. 17: 149-161.

Romero, Florencia de. 1978. «Repercusiones de la revolución de la Paz en Puno». Historia y Cultura. Núm. 3: 189-208.

Vicuña Mackenna, Benjamín. 1971. La independencia en el Perú. Buenos Aires: Editorial Francisco de Aguirre.

Wibel, John Frederick. 1975. The evolution of a regional community within Spanish empire and Peruvian nation: Arequipa, 1780-1845. Tesis de doctorado. Stanford: Stanford University.

Zegarra Meneses, Guillermo. 1973. Arequipa, en el paso de la Colonia a la República. Visita de Bolivar. Segunda edición. Arequipa: [s. e.].

Fecha de recepción: 2/II/2016 Fecha de aceptación: 1/VI/2016 